\title{
Disabling G $\beta \gamma$ SNARE interaction in transgenic mice disrupts GPCR-mediated presynaptic inhibition leading to physiological and behavioral phenotypes.
}

Zack Zurawski ${ }^{1,2}$, Analisa D. Thompson Gray ${ }^{1}$, Lillian J. Brady ${ }^{1},{\text { Brian } \text { Page }^{2} \text {, Emily Church }}^{2}$, Nicholas A. Harris ${ }^{3}$, Michael R. Dohn ${ }^{1}$, Yun Young Yim ${ }^{1}$, Karren Hyde ${ }^{1}$, Douglas P. Mortlock ${ }^{3}$, Danny G. Winder $^{3}$, Simon Alford ${ }^{2}$, Carrie K. Jones ${ }^{1,4}$, Heidi E. Hamm ${ }^{1,5^{*}}$

${ }^{1}$ Department of Pharmacology, Vanderbilt University, Nashville, TN, 37232

${ }^{2}$ Department of Anatomy and Cell Biology, University of Illinois at Chicago, Chicago, IL, 60612

${ }^{3}$ Department of Molecular Physiology and Biophysics, Vanderbilt University, Nashville, TN, 37232

${ }^{4}$ Vanderbilt Center for Neuroscience Drug Discovery, Vanderbilt University, Nashville, TN, 37232

${ }^{5}$ Corresponding author

*Correspondence: heidi.hamm@vanderbilt.edu

\begin{abstract}
$\mathrm{G}_{\mathrm{i} / 0}$-coupled G-protein coupled receptors modulate neurotransmission presynaptically through inhibition of exocytosis. Release of G $\beta \gamma$ subunits decreases the activity of voltage-gated calcium channels (VGCC), decreasing excitability. A less understood $\mathrm{G} \beta \gamma$-mediated mechanism downstream of calcium entry is the binding of G $\beta \gamma$ to SNARE complexes. Here, we create a mouse partially deficient in this interaction.
\end{abstract}


SNAP25 $\Delta 3$ homozygote animals are developmentally normalbut impaired gait and supraspinal nociception. They also have elevated stress-induced hyperthermia and impaired inhibitory postsynaptic responses to $\alpha_{2 A}-A R$, but normal inhibitory postsynaptic responses to $G_{i / 0}$-coupled $G A B A_{B}$ receptor activation. SNAP25 $\triangle 3$ homozygotes have deficits in inhibition of hippocampal postsynaptic responses to $5 \mathrm{HT}_{1 \mathrm{~b}}$ agonists that affect hippocampal learning. These data suggest that $\mathrm{G}_{\mathrm{i} / \mathrm{o}}$-coupled GPCR inhibition of exocytosis through the G $\beta \gamma$-SNARE interaction is a crucial component of numerous physiological and behavioral processes.

\section{INTRODUCTION}

G protein coupled receptors (GPCR) play a primary role in regulating every physiological function and every organ system. They modulate secretion of hormones throughout the body. In the brain, GPCRs activated by neurotransmitters in turn modulate neurotransmission- and voltage-gated ion channels and are critical to proper functioning of brain circuits as well as their alterations in development, especially learning and memory. GPCR modulation occurs through many mechanisms, including second messengers and phosphorylation ${ }^{1}$. In particular, $\mathrm{G}_{\mathrm{i} / \mathrm{o}}$ GPCRs are inhibitory to secretion throughout the body from the periphery to the central nervous system via direct membrane-delimited action through G $\beta \gamma$. In neurons presynaptic modulation of neurotransmitter release occurs at every synapse and is important in avoiding overstimulation by autoreceptors that inhibit the release of specific neurotransmitters as well as for normal functioning of brain circuitry by heteroreceptors. $\mathrm{G}_{\mathrm{i} / \mathrm{o}}$ GPCRs inhibit exocytosis presynaptically through three main membrane-delimited mechanisms: by voltage-dependently inhibiting calcium entry through G $\beta \gamma$ binding to voltage-gated calcium channels (VGCC) ${ }^{2-10}$, by G $\beta \gamma$ activation of G protein-coupled inwardly-rectifying potassium channels ${ }^{11-13}$, leading to membrane hyperpolarization, and by direct interaction of $G \beta \gamma$ with the exocytotic apparatus causing inhibition of exocytosis ${ }^{14-29}$. 
An accepted mechanism of presynaptic inhibition involves $\mathrm{G}_{\mathrm{i} / \mathrm{o}^{-}}$-coupled GPCR modulation of calcium entry at the active zone ${ }^{10,30-33}$. Free cytosolic $\mathrm{Ca}^{2+}$ increases neurotransmitter release with a $4^{\text {th }}$ power non-linear relationship ${ }^{34,35}$ between concentration and exocytosis, and inhibition of $\mathrm{Ca}^{2+}$ entry inhibits exocytosis. Direct G $\beta \gamma$ modulation of VGCC has been demonstrated at the presynaptic terminal with calcium-sensitive dyes ${ }^{25}$ and more directly, electrophysiologically at cell bodies and at the calyceal synapse of Held ${ }^{36,37}$. $\mathrm{G}_{\mathrm{i} / \mathrm{o}}$-coupled GPCRs also inhibit the frequency of spontaneous firing and $\mathrm{Ca}^{2+}$ independent neurotransmitter release through less well-understood mechanisms ${ }^{38-44}$. Direct inhibition of exocytotic fusion controls exocytosis linearly and does not require changes in diffusible cytoplasmic calcium. G $\beta \gamma$ modulates exocytotic fusion by binding the membrane-proximal C-terminal end of the soluble NSF attachment protein receptor (SNARE) complex that brings the vesicle close to the plasma membrane. We have shown that Botulinum Toxin Type-A (BoNT/A) functionally uncouples this direct G $\beta \gamma$-SNARE interaction by cleaving the C-terminal 9aa from SNAP25; in addition, a peptide from this region can itself block the presynaptic inhibition ${ }^{17}$.

In biochemical support of the modulation at the exocytotic machinery, we have shown that G $\beta \gamma$ binds directly to ternary SNARE complexes, as well as to the target membrane-associated (t)-SNARE and the individual SNARE components SNAP25, syntaxin1A, and synaptobrevin2/VAMP2, and competes with the binding of synaptotagmin I to t-SNARE and ternary SNARE complexes ${ }^{16,21}$. In addition, we have shown that $\mathrm{G} \beta \gamma$ mediates a profound inhibition of exocytosis upon the activation of presynaptic Gi/ocoupled $5 \mathrm{HT}_{1 \mathrm{~B}}$ - like receptors ${ }^{15,16,21,25}$.

Modulatory effects of presynaptic GPCRs "downstream of calcium entry" are difficult to measure directly in the presynaptic terminal. This is due to preclusion of direct recording by the small size of the terminal. Many critical questions remain unanswered about the importance of G $\beta \gamma$ regulation of the SNARE machinery in neuromodulation. For example, it is not known which $\mathrm{G}_{\mathrm{i} / \mathrm{o}}$-GPCRs work by this mechanism. In particular, the relative importance of direct inhibition of release at the exocytotic apparatus 
versus other $\mathrm{G}_{\mathrm{i} / \mathrm{o}}$-GPCR evoked molecular events is unknown. Moreover, it is not known whether multiple G $\beta \gamma$ - dependent mechanisms operate synergistically.

To investigate the role of the G $\beta \gamma$-SNARE interaction in normal physiology, we created a transgenic mouse deficient in this interaction using the CRISPR/Cas9 strategy. We focused on the SNAP25 target of $\mathrm{G} \beta \gamma$, because of the difficulty of removing $\mathrm{G} \beta \gamma$, as there are $5 \mathrm{G} \beta$ 's and $12 \mathrm{G} \gamma$ 's, and because we do not know which of them is involved in interaction with the SNARE complex. However, we know that G $\beta \gamma$ binds the C-terminal of SNAP25, and we have determined that SNAP25 33 has a twofold reduction in $\mathrm{G} \beta \gamma$ binding and a two-fold reduction in the serotonin $1 \mathrm{~B}$ receptor $\left(5-\mathrm{HT}_{1 \mathrm{~B}} \mathrm{R}\right)$ mediated inhibition of exocytosis, while evoked release is normal ${ }^{26,45}$. In the current study, we confirmed that C-terminally truncated t-SNARE complexes have a decreased ability to bind G $\beta \gamma$ and inhibit synaptotagmin I-mediated liposome fusion in vitro. Furthermore, we created a transgenic mouse with the SNAP25 $\triangle 3$ mutation. In vivo studies reveal that the SNAP $25 \Delta 3$ mutant animals have significant behavioral and physiological defects in nociception and stress handling, motor coordination, affective behaviors, and cognitive behaviors linked to the central nervous system. This is likely due to suppression of $\mathrm{G}_{\mathrm{i} / \mathrm{o}}$-coupled GPCRmediated inhibition of exocytosis.

\section{RESULTS}

\section{Creation of the SNAP25 33 mouse via CRISPR-Cas9.}

To create a mouse deficient in the G $\beta \gamma$-SNARE interaction, we introduced the SNAP25 $\triangle 3$ mutation into the eighth exon of SNAP25 via the CRISPR/Cas9 interaction. We inserted the SNAP25 33 allele into the wildtype (WT) SNAP25 locus using CRISPR-Cas9 technology. First, sgRNAs targeting the Cterminus of SNAP25 were ligated into the Cas9-containing px330 vector (Fig. 1A). Single-stranded homology donors contained the G204* mutation within the C-terminus of SNAP25 and a HindIII restriction site for genotyping, along with appropriate regions of homology to induce homology-driven repair (Fig. 1A). These DNAs were co-transfected into B6D2 mouse embryos. Transfected embryos 
were implanted into dams and pups were born. Heterozygote pups were bred to obtain viable and fertile homozygotes. PCR genotyping of the pups revealed three heterozygous mice that had undergone homology-directed repair out of 32 pups born (Fig. 1B). To verify the integrity of the regions surrounding the G204* mutation, we performed Sanger sequencing on PCR products from the eighth exon of SNAP25 (data not shown). No mutations other than the G204* mutation and subsequent restriction site in the 3' UTR for genotyping were observed. Heterozygous mice were fertile and were bred to C57BL6/J WT mice to yield homozygous offspring.

Homozygous offspring containing the SNAP25 $\Delta 3$ mutation were viable at all developmental ages and the general health, appearance, and breeding of these mutant mice was unremarkable relative to their agematched littermate WT mice (Fig. 1C1). SNAP25 33 mutant mice also displayed normal growth curves relative to littermate WT mice, with comparable body weights from 3 to 60 weeks of age (Fig. 1C2). The expression levels of a panel of synaptic proteins present in SNAP25 $\Delta 3$ mouse brain homogenate were not significantly different from expression levels for these proteins in the WT animals, except for decreased expression of cysteine string protein (CSP) and complexin 1/2, as assessed by immunoblot (Fig. 1D).

$\mathrm{G} \beta \gamma$ interactions at presynaptic terminals are ubiquitous and loss of a site of interaction at the presynaptic might cause neurodevelopmental defects. Thus, we utilized immunofluorescence microscopy to investigate differences in neuronal morphology between adult WT and SNAP25 $\Delta 3$ animals. Neuronal cell bodies were visualized utilizing a mouse primary antibody against $\mathrm{HuC} / \mathrm{D}^{46}$. Excitatory inputs onto observed soma were visualized using a primary antibody against vGlut2, a marker of glutamatergic synapses, whereas inhibitory inputs were visualized with a primary antibody against vGAT, a marker of GABAergic synapses. No significant differences were detected in the number of synaptic contacts or excitatory/inhibitory inputs between WT and SNAP25 $\Delta 3$ littermates, supporting the notion that observed phenotypes are due to changes in neuronal signaling rather than changes in synaptic proteins or other gross morphological changes (Fig. 1E). 


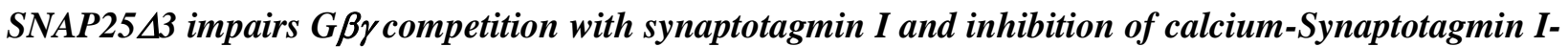

\section{mediated liposome fusion.}

$\mathrm{G} \beta \gamma$ has been shown to mediate its effects on exocytosis via competition with the $\mathrm{Ca}^{2+}$ sensor synaptotagmin I (sytI) for interaction for the C-terminal region of SNAP25 ${ }^{16,21}$. To investigate the in vitro phenotype of the SNAP25 $\Delta 3$ mutation, we utilized TIRF microscopy to determine whether recombinant Alexa Fluor (AF) 488-labeled sytI C2AB domains bound membrane-associated WT and SNAP25 3 tSNARE complexes differently in lipid membranes, and, additionally, the potency for which purified bovine $G \beta_{1} \gamma_{1}$ could compete with AF-sytI for binding sites on these mutant t-SNAREs. Liposomes consisting of $55 \% \mathrm{PC} / 15 \% \mathrm{PE} / 29 \% \mathrm{PS}$ in addition to $1 \% \mathrm{DiD}$ as a tracer harboring WT or mutant $\mathrm{t}$ SNARE complexes were fused into a lipid bilayer via stimulation with $5 \mathrm{mM} \mathrm{CaCl} 2$. After a superfusate $\mathrm{KCl} 150 \mathrm{mM}$ and HEPES 5mM wash, AF-sytI with $100 \mu \mathrm{M}$ free $\mathrm{Ca}^{2+}$ was applied in solution over the cover-slip-supported lipid bilayer. Increasing concentrations of $\mathrm{G} \beta \gamma$ were then applied in this $100 \mu \mathrm{M} \mathrm{Ca}^{2+}$ solution and AF-sytI fluorescence was measured. G $\beta \gamma$ competed with AF-sytI for binding sites on WT tSNARE, causing a concentration-dependent reduction in both absolute fluorescence and anisotropy of the AF-sytI signal, with a half maximal effect at $502 \pm 151 \mathrm{nM}$ (Fig. 2A). Substitution of SNAP25 $\Delta 3$ into the t-SNARE in the lipid bilayer reduced the maximal effect of G $\beta \gamma$ on AF-sytI anisotropy to $47 \pm 13 \%$ of the WT effect (Fig. 2A). These data suggest that C-terminally truncated t-SNARE complexes have a decreased ability to bind G $\beta \gamma$.

G $\beta \gamma$ has been shown to inhibit sytI and SNARE-driven lipid mixing assays in a concentrationdependent manner ${ }^{27}$. A more extensive C-terminal mutation of SNAP25, SNAP25 $\Delta 9$, in which nine residues were truncated had previously been shown to display reduced kinetics and reduced maximum extent of lipid mixing compared to WT SNAP25 in lipid mixing assays ${ }^{47}$. Thus, we investigated whether the SNAP25 33 mutant behaved differently from WT controls in reconstituted vesicle fusion studies with SNARE complexes reconstituted into liposomes containing anionic phospholipids ${ }^{47,48}$ (Fig. 2B) No 
significant difference was observed between SNAP25 3 and WT SNAP25 with regards to the maximum extent of lipid mixing (Fig. 2C1). The basal rate of lipid mixing in the absence of sytI C2AB was not significantly different between SNAP25 $\triangle 3$ and WT.

The reduced efficacy for G $\beta \gamma$ to displace calcium-bound syt1 at SNARE complexes containing SNAP25 3 compared to WT SNAP25 implies that the mutation will modify the ability of G $\beta \gamma$ to interfere with vesicle fusion. Indeed, $\mathrm{G} \beta_{1} \gamma_{1}$ was able to significantly inhibit lipid mixing at a concentration of $2 \mu \mathrm{M}$ in liposomes containing t-SNAREs with WT SNAP25, but not SNAP25 3 (Fig. 2C). G $\beta_{1} \gamma_{1}$ was able to inhibit lipid mixing significantly less well at a concentration of $6 \mu \mathrm{M}$ in liposomes containing t-SNAREs with SNAP25 $\Delta 3$ than liposomes containing SNAP25 WT. Pairwise comparisons between WT and the SNAP25 23 mutant t-SNARE can be found in Fig. 2C2. Together, these data suggest that the SNAP25 $\Delta 3$ mutation impairs G $\beta \gamma$ binding while showing very little effect on lipid mixing or sytI $\mathrm{C} 2 \mathrm{AB}$ function, in accordance with previous results ${ }^{26}$.

\section{SNAP25 33 mice exhibited modest alterations in autonomic and somatomotor nervous system functions}

\section{but enhanced insulin action.}

Membrane delimited $\mathrm{G}$ protein mediated effects are ubiquitous at secretory cells and at presynaptic terminals. $G \beta \gamma$ modifies hormone secretion ${ }^{24}$, and synaptic transmission in the peripheral and central nervous systems $5,6,15,19,28,49$. However, these effects are mediated by more than one target of G $\beta \gamma$ including the SNARE complex. Thus, we next systematically characterized potential changes in the behavioral and/or physiological phenotypes of the SNAP25 $\Delta 3$ homozygotes. To identify any gross neurological deficits, we performed a modified Irwin Neurological Battery ${ }^{50}$ on male homozygote SNAP25 $\Delta 3$ and their age-matched littermate WT mice. This test battery evaluated changes in 25 different autonomic and/or somatomotor nervous system endpoints (see Supplemental Figure 1 for the complete modified Irwin battery results). While the SNAP25 33 mice displayed no change in core body temperature, modest alterations in the aggregate Irwin scores for both the autonomic and somatomotor 
nervous system functions were noted relative to the WT mice reflecting differences in several endpoints, including the corneal and pinna reflexes, leg weakness, and placing loss, a parameter in which the animals is unable to immediately replace its hindlimb in its normal position when moved out of position (Fig. S1A1 and S1A2). These deficits hinted towards the presence of potential impairments in $\mathrm{G}_{\mathrm{i} / \mathrm{o}}$-coupled GPCR signaling and the need to follow-up with more extensive behavioral and physiological characterization of these mice, including assessment of specific autonomic nervous system functions, locomotor coordination, and nociception.

\section{SNAP25 13 mice have impaired motor coordination and altered gait.}

$\mathrm{G}$ protein coupled receptors, including presynaptic receptors, mediate profound effects on locomotor behaviors throughout the neuraxis. These effects range from supraspinal modulation of initiation of behaviors $^{51}$ to modification of output generated within the spinal cord ${ }^{52}$ and involve a number of presynaptically expressed $\mathrm{G}_{\mathrm{i} / \mathrm{o}}$-coupled receptors. To assess potential alterations in locomotor activity in the SNAP25 $\triangle 3$ mouse under baseline or challenge conditions, we evaluated overall locomotor activity using an open-field test. No significant genotype-based differences in the total distance traveled or rearing behaviors were observed at any interval over the entire $60 \mathrm{~min}$ test period in either light or dark conditions for WT and homozygote SNAP25 23 mice (Figure 3A1, 3A2 and Supplemental Fig. S2).

We evaluated the motor coordination, balance, and learning of the SNAP25 $\Delta 3$ mice using a multi-day rotarod paradigm where the latency (in seconds) required for a mouse to drop from a constantly accelerating rotating rotarod was measured over three consecutive days. As shown in Figure 4B, both the male WT and SNAP25 $\triangle 3$ mice showed increased motor learning as denoted by increased latencies to drop from the rotarod on each subsequent day of testing. However, the rate of motor learning was decreased in the SNAP25 33 mice relative to the WT mice over the testing period, with significant differences observed on the second and third days of testing. 
To assess whether the potential differences in the gait of the SNAP25 $\Delta 3$ mice relative to the WT could have contributed to the differences in rotarod learning over time shown in Fig $\mathbf{3 B}$, we evaluated the mice using the TreadScan ${ }^{\bullet}$ gait analysis system ${ }^{53}$ Paw placement and motion of each mouse during running were imaged from below a moving transparent treadmill. Image analysis was performed utilizing TreadScan ${ }^{\circledR}$ software. As shown in Figure 3C, SNAP25 $\Delta 3$ homozygotes exhibited a significant increase in brake duration for all paws other than the rear left paw. Similarly, there was an increase in stance duration in all four paws in SNAP25 3 (Fig. 3D). Across other gait parameters, such as gait angle, run speed, track width, stride frequency, stride length, \% stance, stride duration, swing duration, and propel duration very minor differences were observed between WT and SNAP25 $\Delta 3$ homozygotes (Supplementary Figure S3 A-I). Together, these findings suggest the presence of locomotor deficits under challenge paradigms in the SNAP25 $\Delta 3$ homozygotes, including motor coordination and abnormal gait.

SNAP25 33 mice lack differences in anxiety in the absence of stressors but do have increased rate of helplessness in the forced swim model

Similar to motor control, mood and affect are profoundly modified by GPCRs. An important

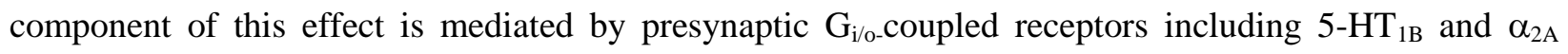
adrenergic receptors, cannabinoid CB1 receptors, dopamine D1 and D2 receptors and group II mGluRs. We sought to investigate potential abnormalities in experimental models related to mood and affect in the SNAP25 23 homozygote mice. Using the light-dark box paradigm ${ }^{54}$ a preclinical model of anxiogeniclike activity, we assessed whether SNAP25 $\triangle 3$ mice would spend more or less time in the light portion of the testing chamber in comparison to the age-matched WT littermates. As shown in Supplementary Fig S4, there were no significant differences detected between WT and homozygote SNAP $25 \Delta 3$ mice in the time spent in the light side of the chamber, transitions between the light and dark sides of the chamber, or 
the distance traveled in the light and dark chambers. These data suggest the absence of an anxiety-like phenotype in SNAP25 $\triangle 3$ homozygotes in the absence of an external stressor.

We performed the forced swim test ${ }^{55}$, a preclinical model for the evaluation of antidepressant efficacy. Age-matched 16-17 week old WT $(n=14)$ and homozygotes $(n=17)$ were placed into an inescapable, water-filled cylinder and the latency to immobility and the total immobility times were recorded. As shown in Figure 4, SNAP25 $\Delta 3$ homozygotes displayed significantly more immobility time (Fig. 4A1) than WTs, as well as a significantly lower latency to immobilization (Fig. 4A2). These initial results are consistent with an interpretation of a potential depressive-like phenotype in the SNAP25 $\Delta 3$ mice.

\section{SNAP25 3 mice show altered supraspinal but not spinal nociception.}

Due to the potential for presynaptic modulatory effects of GPCRs in pain transmission, we follow-up by investigating whether the SNAP25 33 mutation altered either spinal or supraspinal mediated mechanisms of nociception, using the tail flick and hot plate assays, respectively ${ }^{56}$. Surprisingly, SNAP25 $\Delta 3$ mice exhibited a decreased sensitivity to thermal pain in the hot plate paradigm in comparison to age-matched WT littermates (Fig. 4B1) as shown by an increased latency to withdraw or lick the footpad after being placed on a $55^{\circ} \mathrm{C}$ hot plate. However, in the tail flick paradigm (a measure of spinal nociception), no significant change in the latency of a mouse to withdraw its tail from a $55^{\circ} \mathrm{C}$ hot water bath was observed between age-matched SNAP25 $\Delta 3$ homozygotes and WT littermates (Fig. 4B2), indicating that SNAP25 $\Delta 3$ homozygotes have alteration in supraspinal, but not spinal nociception, leading to increased pain thresholds.

\section{SNAP25 33 animals have impaired sympathetic responses and loss of $\alpha_{2 a}$ adrenergic receptor function.}

Presynaptic inhibitory effects of GPCRs were first identified in the autonomic nervous system as autoreceptors controlling noradrenaline release ${ }^{57}$. In the Irwin behavioral screening, we noted several changes in autonomic nervous system function in SNAP25 $\Delta 3$ animals (Fig S1A1). One sympathetic system $\mathrm{G}_{\mathrm{i} / \mathrm{o}}$ GPCR that is known to work through the G $\beta \gamma$-SNARE interaction is the presynaptic 
inhibitory $\alpha_{2 \mathrm{~A}}$-adrenergic receptor $\left(\alpha_{2 \mathrm{~A}}-\mathrm{AR}\right)^{19,24}$. If the inhibitory effects of $\alpha_{2 \mathrm{~A}}$-ARs are perturbed in the SNAP25 $\Delta 3$ homozygotes, we might expect to see elevated stress responses, because this receptor is the noradrenergic inhibitory autoreceptor that regulates the amount of norepinephrine (NE) release in the sympathetic system that controls fight and flight responses ${ }^{58-60}$. To investigate whether the SNAP25 $\Delta 3$ animals have exaggerated stress responses, we performed stress-induced hyperthermia studies in singlyhoused age-matched littermate SNAP25 33 homozygotes and WT littermate controls ${ }^{90}$. In the stressinduced hyperthermia paradigm ${ }^{61}$, handling-based stress produces an increase in body temperature. Rectal temperatures were recorded before and after manual scruffing with an interval of $15 \mathrm{~min}$ between each reading. SNAP25 $\triangle 3$ homozygotes exhibited a twofold greater elevation in body temperature than WT littermates subsequent to handling (Fig. 5A). From this, we concluded that the SNAP25 $\triangle 3$ mutation produces a stress hypersensitivity phenotype.

Based on our findings of exaggerated stress-induced hyperthermia in the SNAP25 33 mutants, we investigated the ability of the $\alpha_{2 \mathrm{~A}}$-AR to inhibit NE release as an autoreceptor ${ }^{58,62}$ as well as glutamate release via heteroceptor mechanisms ${ }^{63-65}$ (Fig. 5B) in age-matched littermate WT and mutant animals. To investigate the functions of $\alpha_{2 \mathrm{~A}}-\mathrm{AR}$ in the SNAP25 $\Delta 3$ mice, we measured the effect of guanfacine, a partial agonist at the $\alpha_{2 \mathrm{~A}}-\mathrm{AR}$, on excitatory glutamatergic transmission in the dorsal bed nucleus of the stria terminalis (dBNST). Guanfacine has been shown to inhibit glutamate release in the BNST via a presynaptic mechanism ${ }^{64}$, at least in part due to inhibition of parabrachial nucleus afferents in the region ${ }^{65}$. Excitatory field potentials were recorded extracellularly as two negative deflections, the tetrodotoxin-sensitive fiber volley potential N1 and the AMPAR antagonist CNQX-sensitive synaptic potential N $2^{63}$ (Fig. 5C). As expected, bath application of guanfacine $(1 \mu \mathrm{M})$ reduced the amplitude of the N2 in WT animals (WT: 23.9. $\pm 1.18 \%$ of baseline $n=10$ slices from 7 animals). Bath application of guanfacine $(1 \mu \mathrm{M})$ attenuated the amplitude of the N2 in SNAP25 $\Delta 3$ animals (SNAP25 $\Delta 3: 8.6 \pm 2.70 \%$, $\mathrm{n}=19$ slices from 10 animals) (Fig. 5D). When compared directly, the reduction in $\mathrm{N} 2$ observed in SNAP25 $\triangle 3$ mice was significantly reduced relative to the change in WT animals (Fig. 5E). To determine 
whether these effects were specific to the $\alpha_{2 \mathrm{~A}}$-AR or were translatable to other $\mathrm{G}_{\mathrm{i} / \mathrm{o}}$-coupled GPCR, we examined the effects of the $\mathrm{GABA}_{\mathrm{B}}$ agonist baclofen on excitatory transmission in the BNST. Bath application of $10 \mu \mathrm{M}$ baclofen inhibited N2 amplitude in both WT (WT: 21.7\%, n=12 slices from 4 animals) and SNAP25 33 mice (SNAP25 $\Delta 3: 19.4 \%, \mathrm{n}=16$ slices from 5 animals ) (Fig. 5F). There was no difference in this inhibition when compared across genotypes (Fig. 5G).

5-HT ${ }_{1 b^{-}}$and $G \beta \gamma-S N A R E-m e d i a t e d$ inhibition of exocytosis are impaired in homozygous SNAP25 3 mutants, while $G_{B B B^{-}}$and $G \beta \gamma-V G C C$ mediated inhibition of exocytosis is normal.

To understand the effect of disruption of the G $\beta \gamma$-SNARE interaction on electrophysiological responses, we studied the $5 \mathrm{HT}_{1 \mathrm{~b}}$-mediated inhibition of hippocampal CA1 to subiculum neurotransmission (Fig. 6A). The subiculum is an essential structure that receives the majority of its input from the hippocampus proper and projects to the entorhinal and other cortices, as well as a variety of subcortical regions. As such, the subiculum plays an important role in spatial and mnemonic information processing, and has been implicated in regulating the response of the hypothalamic-pituitary-adrenal (HPA) axis to stress ${ }^{66}$.

Since $5 \mathrm{HT}_{1 \mathrm{~B}}$ receptors have been shown to inhibit synaptic transmission at CA1 to subicular synapses by modulation of the G $\beta \gamma$-SNARE interaction ${ }^{25}$, we compared the effects of application of the $5 \mathrm{HT}_{1 \mathrm{~B}} \mathrm{R}$ selective agonist CP93129 on hippocampal slices prepared from age-matched WT or SNAP25 $\Delta 3$ animals during field potential recordings in the subiculum after stimulation of CA1 pyramidal neuron axons. The $\mathrm{GABA}_{\mathrm{A}} \mathrm{R}$ and NMDAR antagonists (bicuculline, $10 \mu \mathrm{M}$; D-2 amino-5phosphonopentanoate, D-AP5, $50 \mu \mathrm{M}$ respectively) were applied to allow focus on AMPARmediated EPSPs. The slope of excitatory postsynaptic potentials recorded in WT animals $(\mathrm{n}=$ 8 slices from 6 animals) was inhibited in a concentration-dependent manner; specifically 400, 800, and $1600 \mathrm{nM}$ of CP93129 caused a significant 50, 70, and 80\% decrease in the EPSP slope, respectively (Fig. 6B1, 6B3). By contrast, in hippocampal slices from the SNAP25 $\Delta 3$ animals $(n=$ 
5 slices from 5 animals), 400, 800, and $1600 \mathrm{nM}$ of CP93129 caused only 30, 35, and $40 \%$ decreases in the EPSP slope, respectively (Fig. 6B2, 6B3), a significant difference from EPSP suppression in WT mice. Overall, these data indicate that $5-\mathrm{HT}_{1 \mathrm{~b}}$-mediated inhibition of exocytosis is decreased in the SNAP25 23 animals, suggesting that disruption of $5 \mathrm{HT}_{1 \mathrm{~b}}$-mediated G $\beta \gamma$-SNARE interaction in transgenic animals attenuates presynaptic inhibition.

\section{No change in $\mathrm{GABA}_{B}$-mediated inhibition of neurotransmission from the CA1 hippocampal region to the subiculum is detected in SNAP2543 animals}

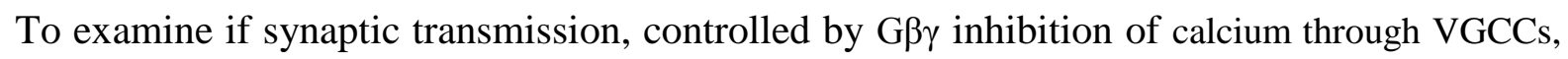
was altered in SNAP25 33 animals, we measured $\mathrm{GABA}_{\mathrm{B}}$-mediated inhibition of neurotransmission in the hippocampal CA1 to subicular synapse. Comparing the effects of application of the selective $\mathrm{GABA}_{\mathrm{B}}$ receptor agonist, baclofen, on field potential recordings in WT and SNAP25 33 animals, we found that there was no change in $\mathrm{GABA}_{B}$-mediated inhibition in the SNAP25 3 animals (Fig. 6C1-3). These data are consistent with the interpretation that $G \beta \gamma$ regulation of calcium entry by baclofen is normal in the SNAP25 $\Delta 3$ animals(n= 5 slices from 5 animals for both WT and SNAP25 $\Delta 3$ ).

In order to determine whether the SNAP25 23 mutation impacted any cognitive functions in the mutant mice, we assessed potential differences between age-matched littermate WT and homozygotes in the Morris water maze task, a well-established preclinical model of hippocampal-mediated learning and memory ${ }^{67,68}$ As shown in Fig. 6D, the WT mice quickly learned the position of the hidden platform in this test by day 2 of training. In contrast, homozygous SNAP25 $\Delta 3$ mice required over 4 days of training to accurately identify the position of the hidden platform, a significant difference in acquisition of this learning/memory. 


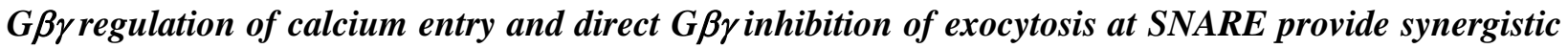

\section{inhibition of postsynaptic responses.}

Fig 7A shows a schematic of the two distinct $G \beta \gamma$-mediated neuromodulatory mechanisms, $\mathrm{GABA}_{\mathrm{B}^{-}}$ and G $\beta \gamma$-mediated inhibition of VGCC and $\mathrm{Ca}^{2+}$ entry, and 5- $\mathrm{HT}_{1 \mathrm{~B}^{-}}$and $\mathrm{G} \beta \gamma$-mediated inhibition of exocytosis via binding the SNARE complex...Consistently, G $\beta \gamma$-SNARE inhibition is more dramatic at the first spike of a train and decreases with calcium buildup, while inhibition through VDCCs is consistent throughout the $\operatorname{train}^{69}$. Because we have shown that there is a temporal pattern to the effects of G $\beta \gamma$ on SNARE mediated exocytosis ${ }^{69}$ we also examined trains of stimuli. When CA1 pyramidal neuron axons were stimulated repetitively to evoke EPSCs and subicular neurons were whole-cell clamped, the inhibition of the postsynaptic response by the $5-\mathrm{HT}_{1 \mathrm{~b}} \mathrm{R}$ selective agonist CP93129 was not sustained, but was attenuated by each consecutive stimulus (blue line, Fig 7B). When plotted as a ratio of inhibition of the first to the fifth stimulus, the response was attenuated $4.6 \pm 0.8$-fold by the fifth stimulus in CP; in baclofen this ratio was $1.1 \pm 0.2$ (Fig 7C). This attenuation in response to $\mathrm{CP}$ is interpreted to be due to

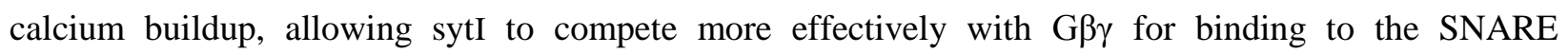
complex $^{21,70}$.

By contrast, inhibition of calcium entry by baclofen is not phasic in nature, generating a similar inhibition of postsynaptic responses at each stimulus (green line, Fig 7B). To determine whether these distinct mechanisms of presynaptic inhibition were additive or more than additive, implying synergism, we examined the impact on inhibition of postsynaptic responses with a simultaneous administration of CP93129 (400nM) and baclofen $(1 \mu \mathrm{M})$. The inhibitory response to this dual stimulation of 5-HT $1 \mathrm{~b}$ and $\mathrm{GABA}_{\mathrm{B}}$ receptors was much greater than additive (red line, Fig 7C). We previously showed that microarchitecture controls GPCRs that work on one or the other mechanism ${ }^{25}$ (Fig. 7A), but this is the first time we have shown that these mechanisms can interact presynaptically.

\section{DISCUSSION}


We have created a transgenic mouse that contains a 3aa truncation of SNAP25 at its C-terminus, the SNAP25 23 mouse, based on our published evidence that this mutant binds G $\beta \gamma$ less well and G $\beta \gamma$ mediated modulation of exocytosis is impaired ${ }^{26}$. This mouse model allows us to probe in vivo effects of decreasing the neuromodulatory effects of $\mathrm{G}_{\mathrm{i} / \mathrm{o}}$ GPCRs that work by liberation of $\mathrm{G} \beta \gamma$ to bind to the SNARE complex and inhibit exocytosis directly. Though this modulatory mechanism has been described in vitro ${ }^{14-17,21,26}$, this is the first report of in vivo phenotypes caused by its loss.

The extreme C-terminus of SNAP25 is a conserved region important for G $\beta \gamma$ binding.

Multiple independent groups have demonstrated that the SNAP25 $\Delta 3$ mutant is not deleterious to exocytosis in neurons and chromaffin cells ${ }^{26,45}$. Furthermore, no other SNARE-binding proteins identified to date have been shown to utilize the C-terminal three residues of SNAP25 as a critical site of interaction except G $\beta \gamma$. This allowed us to selectively examine the impact of G $\beta \gamma$-SNARE interactions in vivo. G $\beta \gamma$ directly competes with sytI for binding to t-SNARE made with SNAP25 WT, while it is less able to compete with sytI for binding to tSNARE made with SNAP25 3 (Fig. 2A). We confirmed that t-SNARE complexes made with SNAP25 $\Delta 3$ do not have defects in synaptotagmin I-stimulated liposome fusion (Fig. 2C), with a maximal extent of lipid mixing not different from wild-type t-SNAREs. In addition, G $\beta \gamma$-mediated inhibition of $\mathrm{Ca}^{2+}$-sytI and SNARE-dependent lipid mixing was reduced with t-SNARE complexes made with SNAP25 $\triangle 3$ (Fig. 2C1, C2). Taken together, these data suggest that the specific phenotypes observed in SNAP25 33 homozygote neurons are due to a decreased ability of G $\beta \gamma$ to bind SNARE complexes and displace sytI at the terminal.

G $\beta \gamma$ binding to the C-terminal region of SNAP25 was first identified by the effects of BoNT/A cleavage of its C-terminal 9 residues on synaptic modulation ${ }^{17}$. G $\beta \gamma$ liberated from $5 \mathrm{HT}_{1 \mathrm{~B}}$ receptors inhibits exocytosis by displacing $\mathrm{Ca}^{2+}$-dependent sytI binding to t-SNARE ${ }^{16,21,27}$. This results in a phasic inhibition of synaptic transmission as calcium buildup during a train of action potentials allows sytI to compete more effectively with G $\beta \gamma$ for binding to the SNARE complex ${ }^{21,70}$. As predicted, 
injection of EGTA was shown to eliminate the phasic inhibition during trains ${ }^{21,70}$. Biochemically, competition between G $\beta \gamma$ and sytI depends upon the concentrations of both G $\beta \gamma$ and sytI, demonstrating this competition between $\mathrm{G} \beta \gamma$ and $\mathrm{Ca}^{2+}{ }^{2+}$-sytI interactions with the t-SNARE complex ${ }^{21}$. The ability of G $\beta \gamma$

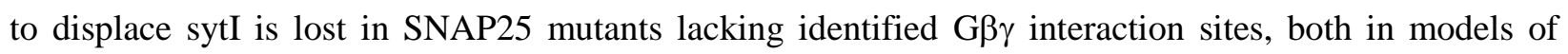
binding in aqueous solution and in models in which the SNARE complex is embedded in lipid bilayers $^{16,21,27}$. In this study, we have confirmed that G $\beta \gamma$ competes less well with sytI for binding to tSNARE made with SNAP25 $\triangle 3$ than with t-SNARE made with SNAP25 WT (Fig. 2A). As predicted, G $\beta \gamma$-mediated inhibition of $\mathrm{Ca}^{2+}$-sytI and SNARE-dependent lipid mixing was reduced with t-SNARE complexes made with SNAP25 3 (Fig. 2 C1, C2).

Conservation of the amino acid sequence in the C-terminus of SNAP25 is extremely high, particularly with regards to the C-terminal nine residues, which are conserved between mammals, birds, and reptiles, pointing to the evolutionary importance of this region. Vectorial assembly of the SNARE complex proceeds from the $\mathrm{N}$ - to the $\mathrm{C}$-terminus ${ }^{71}$, and the $\mathrm{C}$-terminal region of the zippering SNARE complex is crucial for the generation of force leading to fusion pore formation. A truncation of the C-terminal 9 residues of SNAP25 leads to smaller foot currents and reduced fusion pore conductances ${ }^{72,73}$, consistent with impaired vesicle-surface fusion events. Thus, it is very interesting that G $\beta \gamma$ binding to the extreme C-terminus modifies fusion properties ${ }^{74}$ and inhibits exocytosis, suggesting that it may interfere with fusion pore opening. Structural studies on the nature of the G $\beta \gamma$-SNARE complex would elucidate the nature of this inhibitory mechanism.

The high conservation of this region may also be required for tight control over exocytosis via regulation by $\mathrm{G}_{\mathrm{i} / \mathrm{o}}$-GPCRs of the $\mathrm{G} \beta \gamma$-SNARE interaction, which is present even in extremely primitive vertebrates such as lamprey. In fact, we first discovered this phenomenon in the primitive cartilaginous fish sea lamprey, which had the advantage of giant axons in their spinal cord, because of lack of myelination, allowing us to inject proteins presynaptically ${ }^{15,17}$. 


\section{Clear in vivo delineation of $G \beta \gamma$ functions in regulating exocytosis}

In SNAP25 $\Delta 3$ animals, both the $\alpha_{2 \mathrm{~A}}$-ARs and the $5 \mathrm{HT}_{1 \mathrm{~b}} \mathrm{R}$, which have previously been shown to work at least partially through G $\beta \gamma$-SNARE ${ }^{19,25,75}$ are unable to inhibit exocytosis to the same extent as WT littermates. By contrast, in both the hippocampus and the BNST of SNAP25 $\Delta 3$ animals, there is no effect on $\mathrm{G} \beta \gamma$ inhibition of exocytosis through the $\mathrm{GABA}_{\mathrm{B}}$ receptor, which is known to work through modulation of calcium entry. This is clear evidence that $G \beta \gamma$ responses through voltage-gated calcium channels- the major other membrane-delimited mechanism regulating neurotransmission- have not been perturbed by the SNAP25 33 mutation. Interestingly, receptors working through both modulatory mechanisms can be present in the same synapse, as shown in recent electrophysiological studies in hippocampus ${ }^{25}$.

\section{Different roles of the two mechanisms of presynaptic neuromodulation}

While we do not know in most cases which mechanisms are activated by different GPCRs, and, in fact, this may be different in different neurons ${ }^{29}$, we do know that individual synapses can contain multiple $\mathrm{G}_{\mathrm{i} / \mathrm{o}}$ GPCRs. As previously reported ${ }^{69}$ and as follows from direct G $\beta \gamma$ competition with sytI SNARE interactions (Fig 2A), the effects of G $\beta \gamma$-SNARE interaction are attenuated in response to trains of action potentials, because of buildup of residual $\mathrm{Ca}^{2+}$ during the course of a stimulus train ${ }^{17}$. As $\mathrm{Ca}^{2+}$ concentrations in the presynaptic terminal rise, calcium-sytI becomes a better competitor of G $\beta \gamma$ at the SNARE complex and G $\beta \gamma$ inhibition decreases ${ }^{21}$ (Fig. 7A). This opens the possibility that other signal transduction mechanisms within the presynaptic terminal can act synergistically with the G $\beta \gamma-\mathrm{SNARE}$ interaction. For example, at the CA1-subicular synapse, 5-HT $1 \mathrm{~B}$ agonists cause $\mathrm{G} \beta \gamma$ to interact directly with the SNARE complex. At the same synapse, $\mathrm{GABA}_{\mathrm{B}}$ receptors inhibit presynaptic $\mathrm{Ca}^{2+}$ entry, so during trains $\mathrm{GABA}_{\mathrm{B}}$ receptor activation reduces action potential-mediated increases in $\mathrm{Ca}^{2+}$ concentration. When both receptors are activated, decreased residual $\mathrm{Ca}^{2+}$ buildup by $\mathrm{GABA}_{\mathrm{B}}$ receptor activation substantially magnifies the 5-HT mediated inhibition during the stimulus train, leading to 
profound presynaptic inhibition. Such a dual modulation, which has never been shown previously, substantially increases the repertoire of presynaptic inhibition, potentially providing much greater control of transmission than either mechanism alone.

The two modulatory mechanisms have very different characteristics. G $\beta \gamma$ 's inhibition of VDCCs is highly sensitive and powerful, but easy to saturate, whereas G $\beta \gamma$-SNARE interaction right at the final step of membrane fusion is stoichiometric (i.e. one or two G $\beta \gamma$ per SNARE) and phasic, based on $\mathrm{Ca}^{2+}$-syt interactions, and thus may provide a much broader dynamic range of modulation that is more difficult to

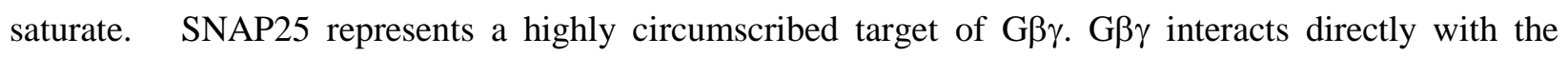
SNARE complex providing a mechanism to modulate vesicle fusion, but without other known downstream effectors. The C-terminal region of SNAP25 has been shown to be critical for forces associated with fusion pore, formation and stability ${ }^{71,73,76}$. Indeed, consistent with this important role of the C-terminal region in fusion pore dynamics, G $\beta \gamma$ interaction with this target modifies fusion properties themselves as a mechanism of presynaptic inhibition ${ }^{70,74,77}$. Receptors that simultaneously target presynaptic $\mathrm{Ca}^{2+}$ channels, in contrast, mediate a much broader range of presynaptic effects, from modifying action potential shape, to altering release probability, as well as modulating G $\beta \gamma$ effects at the SNARE complex by altering $\mathrm{Ca}^{2+}$ accumulation during stimulus trains.

\section{Dramatic effects of the SNAP25 23 mutation on stress.}

As expected, stress responses in SNAP25 $\Delta 3$ homozygotes were significantly enhanced, given that the major adrenergic autoreceptor which inhibits norepinephrine release works through this mechanism ${ }^{78}$. This behavioral phenotype was followed up with treatment of brain slices from these mice with guanfacine, a $\alpha_{2 \mathrm{~A}}-\mathrm{AR}$ selective agonist. We showed that the effect of guanfacine on excitatory glutamatergic transmission in the dorsal BNST, a component of the extended amygdala, was nearly eliminated in homozygous SNAP25 $\triangle 3$ mice. Previous work has suggested that this receptor presynaptically regulates excitatory input in the extended amygdala via a G $\beta \gamma$ and BoNT sensitive 
mechanism ${ }^{19}$. Our results here provide further support for such a mechanism at these glutamatergic synapses. Heteroreceptor effects of $\alpha_{2 \mathrm{~A}}$-AR agonists such as those shown here have been shown to have dramatic outcomes on both physiologies within the extended amygdala ${ }^{63-65}$ as well as on whole-organism behavior $^{78,79}$. Specifically, heteroreceptor $\alpha_{2 \mathrm{~A}}$-ARs have been shown to be responsible for the sedation, anesthetic sparing, hypothermia, analgesia, bradycardia, and hypotension induced by systemic administration of $\alpha_{2 \mathrm{~A}}$-AR agonists ${ }^{56}$. This contrasts with the autoreceptor $\alpha_{2 \mathrm{~A}}$-ARs, which are responsible for physiologic feedback inhibition of NE release and spontaneous locomotor activity ${ }^{78}$. The relative contributions and deficits of auto- and hetero-receptor $\alpha_{2 \mathrm{~A}}$-ARs to the stress-related phenotypes observed in the SNAP25 $\triangle 3$ mouse remain unclear and will be the focus of future studies investigating the mechanisms underlying the ability of $\alpha_{2 \mathrm{~A}}$-AR agonists to block the ability of stress to impact neurotransmission $^{80}$, depression- and anxiety-related phenotypes ${ }^{81,82}$ and drug-seeking behavior in rodent models of addiction $^{83-85}$.

Chronic disruption of the G $\beta \gamma$-SNARE interaction leads to a number of behavioral and physiological phenotypes.

Prior studies have highlighted the physiological settings in which the G $\beta \gamma$-SNARE mechanism is critical for the regulation of vesicle release by $\mathrm{G}_{\mathrm{i} / \mathrm{o}}$-coupled GPCRs in a variety of secretory cell types, including multiple populations of neurons in the amgydala, cerebellum, spinal cord, and hippocampus ${ }^{15,19,20,49}$, chromaffin cells $^{22}$, the beta cells of the islets of Langerhans ${ }^{24}$, and cone photoreceptors $^{28}$. Here, we expand upon these existing findings in multiple ways. For many years, presynaptic receptors have been thought to work mainly through modulation of calcium entry by inhibiting $\mathrm{VGCC}^{2-10}$, or by activating GIRK channels ${ }^{86,87}$. Using the SNAP25 $\Delta 3$ mouse as a model of deficiency in the G $\beta \gamma$-SNARE pathway, we demonstrated that multiple deleterious behavioral phenotypes associated with stress, locomotion, pain processing and spatial learning were detected upon selective inhibition of G $\beta \gamma$-SNARE interaction, as well as increased immobility in forced swim tests associated 
with depressive-like phenotype, implying downstream physiological and pathophysiological consequences for disruption of the G $\beta \gamma$-SNARE pathway.

Though severe physiological consequences exist for SNAP25-null homozygotes, neither neonatal lethality nor gross deficits in exocytosis are observed in the SNAP25 $\Delta 3$ homozygotes. Physiological consequences for disruption of SNAP25 function are also observed in the SNAP25b-deficient homozygotes, in which the exon specific to SNAP25b is replaced by a second SNAP25a exon ${ }^{88}$, producing spontaneous seizures and a number of behavioral deficits. Locomotor deficiencies in the rotarod test were observed in the SNAP25 33 homozygotes, similar in magnitude to the SNAP25 I67T homozygotes termed the "blind-drunk mouse" $"$, although the SNAP25 $\Delta 3$ homozygotes lacks any of the deficits observed in the light-dark box test present in the I67T homozygotes. It is uncertain if the spatial learning deficits observed in the SNAP25b- deficient mouse in tasks such as the Morris water maze would similarly be observed in the SNAP25 3 homozygotes. However, neither deficits in the elevated zero/plus maze paradigm nor spontaneous seizure activity were observed in the SNAP25 $\Delta 3$ homozygotes. A comparison of the phenotypes of the highly selective mutation in the SNAP $25 \Delta 3$ mice versus phenotypes detected in the SNAP25 null and SNAP25 I67T mice will help identify the particular molecular interactions, and the affinity/probability of these interactions, for more selective therapeutic target strategies, especially since expression levels of other presynaptic proteins, such as syntaxin 1a and Munc18, were not altered in SNAP25 $\Delta 3$ homozygotes.

The significant phenotypes displayed by SNAP25 33 homozygotes in many behavioral paradigms are clear evidence that $\mathrm{G}_{\mathrm{i} / \mathrm{o}}$ GPCR regulation of $\mathrm{G} \beta \gamma$ binding to the exocytotic fusion machinery is required for normal physiological and behavioral function. Based on the profile of these physiologic and behavioral alterations, we are particularly interested in the GPCR identity and circuitry basis of the presynaptic inhibitory action of GPCRs underlying these changes. Unfortunately, this is not possible to determine in these animals, since we do not know which $\mathrm{G}_{\mathrm{i} / \mathrm{o}}$-coupled GPCRs work through this 
mechanism. In addition, since the SNAP25 $\Delta 3$ mutation is found in all cells, further circuit-based studies will need to be carried out to understand the basis of the SNAP25 33 phenotype. For example, viral expression of the SNAP25-8A mutation that has no affinity for $\mathrm{G} \beta \gamma^{14}$ will be used in future studies to further define the circuitry underlying these behavioral phenotypes. Nevertheless, some circuit implications for these receptors can be made from experiments targeting specific receptor subtypes, with known and selective efficacy at the SNARE complex. These effects are consistent with defects found in the SNAP25 $\Delta 3$ homozygous mice. In the lamprey spinal cord $5-\mathrm{HT}_{1 \mathrm{~B} / 1 \mathrm{D}}$-like receptors are found on glutamatergic terminals of the descending motor command system and the locomotor pattern generator. Activation of these receptors in lamprey mimics the known effects of 5-HT application in all vertebrate models of locomotion, in which locomotor frequency is lowered ${ }^{70,90}$ Loss of these receptor mediated effects in intact animals would be expected to lead to a loss of locomotor coordination and a reduction in the range of locomotor frequencies the animal can achieve.

These studies provide a basis for the hypothesis that the G $\beta \gamma$-SNARE interaction and modulation of exocytosis downstream of presynaptic calcium entry is an important neuromodulatory mechanism in a large diversity of circuits, mediating multiple physiologic behaviors. Future studies will focus on identifying the $\mathrm{G}_{\mathrm{i} / \mathrm{o}}$-coupled GPCRs that signal via G $\beta \gamma$-SNARE implicated in these behavioral and electrophysiological studies, and determining transcriptional signatures and pathologies related to this mechanism.

\section{METHODS:}


Transgenic embryo generation. The SNAP25 $\Delta 3$ mouse was created with assistance from the Vanderbilt Transgenic Mouse and Embryonic Stem Cell Resource in compliance with protocols approved by the Vanderbilt Institutional Animal Care and Use Committee. Transgenic mouse embryos were generated utilizing the CRISPR/Cas9 system. The protospacer targeting construct was generated via a 24-mer oligo with a forward sequence of5'CACCGCAACAAAGATGCTGGGAAG3' annealed to 5'AAACTTCCCAGCATCTTTGTTGC 3'. $1 \mu \mathrm{g}$ of px330 vector (Zhang lab, MIT) was digested in a stoichiometric fashion with Bbs1 (NEB) to a final concentration of $50 \mathrm{ng} / \mu \mathrm{L}$ for $1 \mathrm{~h}$ at $37 \mathrm{C}$. The oligo was then ligated into the digested product with Quick Ligase (NEB) in a one-pot reaction in which oligo was added to a final concentration of $0.4 \mu \mathrm{M}$. and ligated for $4 \mathrm{~m}$ at $25 \mathrm{C}$. Constructs were verified via Sanger sequencing. The single-stranded homology donor(IDT, Ultramer) was 126bp in length and spanned the C-terminal final exon of SNAP25 with 48bp of homology in either direction of the site of interest along with the G204* mutation and a HindIII site 3' of the G204* for the purposes of sequencing. The px330 vector and single-stranded homology donor were co-microinjected into the pronucleus of 587 B6D2 embryos, 447 of which were implanted into 40 B6D2 dams. 32 pups were obtained, two of which contained the G204* mutation in germline cells as measured by PCR analysis of genomic DNA. To verify that the inserted transcript was correct, PCR products were then excised and ligated into pCR2.1TOPO, which was then subjected to Sanger sequencing using M13 and T7 primers. No changes other than the addition of the G204* and HindIII site were observed.

Mouse breeding and genotyping. Littermate cohorts in this study carry a mixed genetic background of $75 \% \mathrm{C} 57 \mathrm{BL} / 6 \mathrm{~J}$ and $25 \% \mathrm{DBA} 2$. The presence of the G204* mutation in the SNAP25 $\Delta 3$ mouse was verified via PCR and Sanger sequencing. Genomic DNA was extracted from the fecal epithelium (Zymo Research) of weaned animals, and homozyogous SNAP25 33 animals were differentiated from WT littermates using two separate PCR reactions. Genomic DNA was amplified using a common reverse primer GGATTGTGGCAGTAGCTCG with diagnostic forward primers: the SNAP25 $\triangle 3$-specific forward primer had the sequence 5' GATGCTGTAAGCTTAGTGG 3', while the WT-specific forward 
primer had the sequence 5' GCAACAAAGATGCTGGGAAGTGG 3'. Amplicons generated are 467 bp and 459 bp respectively for SNAP25 3 and WT mice and were analyzed via agarose gel electrophoresis.

Plasmids- The open reading frames for syt I 96-421 was subcloned into the glutathione-s-transferase (GST) fusion vector, pGEX6p-1 ${ }^{91}$, (GE Healthcare, Chalfont St. Giles, Buckinghamshire, UK) for expression in E.coli. t-SNARE complexes consisting of SNAP25 and syntaxin1A were purified from the dual-expression vector pRSF-Duet1 with a subcloned N-terminal-His tag on SNAP25 $5^{92}$ C-terminally Histagged synaptobrevin was produced from the plasmid $\mathrm{pTW} 2^{48}$. The sequence corresponding to a gRNA specific to the final exon of SNAP25 was cloned into pX330-U6-Chimeric_BB-CBh-hSpCas9 ${ }^{93}$, which was a gift from Feng Zhang (Addgene plasmid \# 42230). t-SNAREs containing SNAP25 33 were produced via point mutagenesis of the WT SNAP25 sequence in pRSF-Duet1 using the method of overlapping primers. pCR2.1TOPO was obtained from Invitrogen.

Immunoblotting. For the immunoblot analysis, SNAP25 (Santa Cruz, sc-376713, 1:500), SNAP23 (Abcam, ab3340,1:500), cysteine string protein (Abcam, ab90499, 1:1000), tomosyn (Santa Cruz, Sc136105, 1:1000), Hsc70 (Abcam, ab154415, 1:1000), Munc13-1 (Synaptic Systems, 126102, 1:1000), munc18-1 (Abcam, ab3451, 1:3000), synaptotagmin7 (Synaptic Systems, 105173, 1:1000), VAMP2 (Synaptic Systems, 104211, 1:1000), synaptotagmin1 (Synaptic Systems, 105-011, 1:1,000), complexin 1/2 (Synaptic Systems 122002, 1:500), syntaxin-1 (Santa Cruz, sc-12736, 1:2,000), and $\beta$-actin (Abcam, ab8227 1:5000) were used. HRP-conjugated secondary antibodies were obtained from Perkin-Elmer and used at the following dilutions: goat anti-mouse $(1: 10,000)$, and goat anti-rabbit $(1: 10,000)$. Images were analyzed for densitometry using ImageJ (available from http://rsbweb.nih.gov/ij/index.html). All statistical tests were performed using GraphPad Prism v.4.0 for Windows, (GraphPad Software, La Jolla, California, USA, www.graphpad.com).

Synaptosome preparation, fractionation, and lysate protocol. Crude synaptosomes were prepared, fractionated, and lysed from mouse brain tissue, as described previously ${ }^{94}$. Various synaptic proteins were detected in lysate of whole crude synaptosomes and presynaptic fractions. 
Protein purification and labeling. Recombinant bacterially expressed syntaxin1A and 6xHisSNAP25 (both WT and SNAP25 33 mutants) were expressed in tandem and purified from E.coli strain BL21, while 6xHisVAMP2 was purified separately. GST-syt I 96-421 was purified separately on glutathioneagarose beads. All four were purified according to previously published methods $s^{27,47,48}$. G $\beta_{1} \gamma_{1}$ was purified from bovine retina as described previously ${ }^{95}$. Purified syt I C2AB was buffer exchanged into 25 mM HEPES pH 7.4, $150 \mathrm{mM} \mathrm{NaCl}, 1 \mathrm{mM}$ TCEP, and 10\% glycerol and labeled at a 20-fold excess with Alexa Fluor 488-C5-maleimide at RT for $2 \mathrm{H}$ before excess probe was removed with an Amicon centrifugal filter with a molecular weight cutoff of 10,000 .

Preparation of liposomes for fusion and TIRF assays. Small unilamellar liposomes containing tSNARE complexes or VAMP2 were made as described previously ${ }^{27,47,48}$. A volume of $55 \%$ POPC (1Palmitoyl-2-Oleoyl-sn-glycero-3-phosphocholine), 15\% DOPS (1,2-dioleoyl-sn-glycero-3-phospho-Lserine (sodium salt) and 30\% POPE (1-Palmitoyl-2-Oleoyl-sn-glycero-3-phosphoethanolamine) in chloroform that would be equal to $15 \mathrm{mM}$ of lipids in $100 \mu \mathrm{l}$ were dried to a lipid film in a glass vial under argon, followed by vacuum removal of residual chloroform. Liposomes containing VAMP2 included $1.5 \% \quad 1.5 \%$ N-(7-nitro-2-1,3-benzoxadiazol-4-yl)-1,2-dipalmitoyl phosphatidylethanolamine (NBD-PE) and $1.5 \% \mathrm{~N}$-(lissamine rhodamine B sulfonyl)-1,2-dipalmitoyl phosphatidylethanolamine (Rhodamine-PE), along with 55\% POPC/15\% DOPS/27\% POPE. $0.4 \mathrm{mg}$ of t-SNARE dimer or 95uL of VAMP2 was added to each tube of lipids in tandem with elution buffer $25 \mathrm{mM}$ HEPES-KOH; pH 7.8, $400 \mathrm{mM} \mathrm{KCl}, 500 \mathrm{mM}$ imidazole, $10 \%$ glycerol, $5 \mathrm{mM}$ 2-mercaptoethanol, $1 \%$ n-octylglucoside) to a final volume of $500 \mu \mathrm{l}$ and subjected to mild agitation until the lipid film was fully dissolved. Liposomes were then formed via the addition of 2 volumes of reconstitution buffer (25 mM HEPES$\mathrm{KOH}, \mathrm{pH} 7.8 ; 100 \mathrm{mM} \mathrm{KCl} ; 1 \mathrm{mM}$ DTT; $10 \%$ glycerol;) in a dropwise manner, followed by additional mild agitation for 10 minutes. The solution was then dialyzed (10,000 molecular weight cutoff) twice for six hours in $4 \mathrm{~L}$ of reconstitution buffer to remove residual detergent. Solutions were mixed with equivalent volumes of $80 \%$ iohexol (Accudenz, Accurate Chemical Co.) and were purified on a 
0\%/30\%/40\% iohexol gradient in a Beckman SW-55 swinging bucket rotor. Liposomes were harvested from the $0-30 \%$ interface and flash-frozen at $-80^{\circ} \mathrm{C}$. Lipid concentrations and recovery rates were obtained using the Beer-Lambert law with NBD-PE absorbance at 460nm from v-SNARE liposomes containing NBD-PE that were maximally dequenched via the addition of docdeylmaltoside to $0.5 \%$. SNARE protein concentrations in VAMP2 and t-SNARE liposomes were determined via Coomassie Brilliant Blue R-250 staining of SDS-PAGE gels containing a standard curve of bovine serum albumin (Thermo Scientific) followed by densitometric analysis of pixel intensity of syntaxin1A bands utilizing the Fiji distribution of ImageJ software ${ }^{96,97}$. SNARE copy number in liposomes was determined according to previously published methods ${ }^{47}$.

In membrane TIRF imaging: Lipid bilayers were prepared from liposomes containing 55\% $\mathrm{PC} / 15 \% \mathrm{PE} / 29 \% \mathrm{PS}$ in addition to $1 \% \mathrm{DiD}$ (3,3'-Dioctadecyloxacarbocyanine perchlorate) with or without t-SNARE complexes containing WT or mutant SNAP25. TIRF imaging studies were conducted according to previously published methods ${ }^{27}$. A shallow volume (to $\sim 150 \mathrm{~nm}$ above the cover slip) was illuminated using TIRF on a custom microscope utilizing a laser launch with $488 \mathrm{~nm}$ solid state and 633 $\mathrm{nm} \mathrm{HeNe}$ lasers whose output intensities were controlled using a Acoutic-Optical-Transmission Filter (AOTF, Prairie Technologies). $488 \mathrm{~nm}$ laser intensities at the microscope input used to illuminate fluorescently tagged proteins were 2 to $5 \mathrm{~mW}$. This beam was offset and focused on the objective backplane (Olympus PlanApoN 60x 1.45 TIRFM) using a modified TIRF laser launch (Olympus IX2). Coverslips were $0.17 \mathrm{~mm}$ borosilicate glass. After laying down lipids in a $5 \mathrm{mM} \mathrm{CaCl}$-containing $^{-}$ solution, a superfusate of $\mathrm{KCl} 150 \mathrm{mM}$ and HEPES 5mM washed the lipid. Then AF-sytI with $100 \mu \mathrm{M}$ free $\mathrm{Ca}^{2+}$ was applied in solution over the cover-slip-supported lipid bilayer..The $633 \mathrm{~nm}$ excitation was used to focus the TIRF illumination on the bilayer. Simultaneously, the intensity and polarization of 535nm fluorescence emitted from Alexa Fluor 488-labeled syt1 C2AB (AF-syt1) was measured by capturing $\mathrm{P}$ and $\mathrm{S}$ polarized emission across a polarizing cube beamsplitter ${ }^{27}$. The focus and setting of the TIRF field used a camera in the inverted configuration light path. Emission was detected and quantified through a second water immersion lens to minimize loss of polarity in emission, with 
excitation light polarity in plane with one detector and orthogonal to another after a polarizing beam splitter.

\section{Behavioral Studies}

\section{Subjects}

All studies were conducted in adult male wildtype and SNAP25 $\Delta 3$ homozygote mice that were breed in house as described above and group-housed unless specified under a 12/12 h light-dark cycle with water available ad libitum. All behavioral studies were evaluated in cohorts of age-matched, littermate controlled wildtype and SNAP25 $\Delta 3$ homozygote mice. All animal experiments were approved by the Vanderbilt University Animal Care and Use Committee and experimental procedures conformed to guidelines established by the National Research Council Guide for the Care and Use of Laboratory

Animals. All efforts were made to minimize animal suffering and the number of animals used. Modified Irwin Neurological Test Battery and Body Weights. This test battery evaluated changes in 25 different autonomic and/or somatomotor nervous system endpoints using the Modified Irwin Neurological Test Battery $^{50}$ in age-matched littermate male SNAP25 $\Delta 3$ homozygotes $(n=21)$ or wild-type $(n=17)$ of $14-15$ weeks of age. All data were manually collected by an experimenter blinded to genotype. Data were represented as the aggregate mean scores for all of the autonomic or somatomotor nervous system endpoints of the Irwin test battery per genotype and were analyzed by Student's t-test using GraphPad Prism. Differences were evaluated using a rating scale from $0-2$ with $0=$ no effect, $1=$ modest effects, $2=$ robust effect. The aggregrate mean scores were extrapolated by calculating the sum of each Irwin parameter for all mice tested. Then the mean of all of the autonomic or somatomotor parameters were calculated. Data are represented as means \pm SEM and were analyzed by Student's two-tailed t-test using GraphPad Prism. In addition, total body weight in grams (g) was measured between 3-60 weeks of age for WT and SNAP25 $\triangle 3$ homozygote mice. Data are presented as means \pm SEM and were analyzed by two-way ANOVA using GraphPad Prism. 
Stress induced hyperthermia assay. Singly-housed male SNAP25 33 homozygotes or wild-type littermate controls were allowed to acclimate to the testing room for 60 minutes. Baseline temperature was taken by inserting a BAT-12 Microprobe Thermometer, dipped into mineral oil, $2 \mathrm{~cm}$ into the rectum for each mouse for $20 \mathrm{~s}$ to obtain core body temperature $\left(T_{1}\right)$. After a 15-min interval, core body temperature for each mouse was measured a second time $\left(T_{2}\right)$. Stress-induced hyperthermia was calculated as the change in core body temperature between the first and second temperature readings $(\Delta T$ $=T_{2}-T_{1}$ ) based on previously published methods ${ }^{61}$ Data are presented as means \pm SEM and were analyzed by Student's two-tailed t-test using GraphPad Prism.

Locomotor Activity Assay. Open field activity was tested in age-matched 10-12 week old male WT $(\mathrm{n}=15)$ and homozygote SNAP25 $\triangle 3$ animals $(\mathrm{n}=14)$ using an open field system (OFA-510, MedAssociates, St. Albans, VT) with three $16 \times 16$ arrays of infrared photobeams as previously described $^{98}$. Total number of photobeam breaks were collected over 60 min under light or infrared lighting conditions. Data were calculated as either the mean distance traveled $(\mathrm{cm}) \pm$ SE for the number of photobeam breaks/5 $\mathrm{min}$ bin/genotype, the total distance traveled (mean horizontal and vertical beam breaks/30 mins) or the total rearing behavior (mean vertical beam breaks/30 mins. Data are presented as means \pm SEM and were analyzed by two-way ANOVA (mean distance traveled) and Student's two-tailed t-test (total distance traveled and rearing) using GraphPad Prism.

Tail-Flick Test. Age-matched littermate male SNAP25 33 homozygotes or WT controls were assessed in the tail-flick assay, a preclinical model of acute spinal-mediated thermal nociception ${ }^{56}$. All mice had their tails individually immersed in a water bath maintained at $55^{\circ} \mathrm{C}$, and the latency to removal in sec was measured. If an animal did not flick its tail within $10 \mathrm{~s}$, it was removed and assigned a response time of 10 
s. Data are presented as means \pm SEM and were analyzed by Student's two-tailed t-test using GraphPad Prism.

Hot Plate Test. Age-matched littermate male SNAP25 33 homozygotes or WT controls were assessed in the hot plate assay, a preclinical model of acute supraspinal-mediated thermal nociception ${ }^{87}$. All mice were individually placed on a hot plate maintained at $50-55^{\circ} \mathrm{C}$ and the latency to lick the front or hind paws was recorded for each mouse. Animals not responding within $30 \mathrm{~s}$ were removed and assigned a score of 30 s. Data are presented as means \pm SEM and were analyzed by Student's two-tailed t-test using GraphPad Prism.

Rotarod assay. Age-matched 10-12 week old male WT $(\mathrm{n}=15)$ and homozygote SNAP25 $\triangle 3$ animals $(n=14)$ were assessed for their ability to maintain balance upon a rotating cylinder undergoing constant acceleration from 4 to $40 \mathrm{RPM}^{99}$. The cylinder was $3 \mathrm{~cm}$ in diameter and each animal was confined to approximately $6 \mathrm{~cm}$ of cylinder length via the use of Plexiglas dividers. Cylinders were suspended $25 \mathrm{~cm}$ above a lever that actuates the timer, resulting in a stoppage of the timer to permit tabulation of the latency required for the animal to fall off the cylinder. The maximum length for each trial was $300 \mathrm{sec}$, at which point a maximum latency value of 300 was tabulated. Trials were conducted for three consecutive days. Data for each day were represented as the mean latency to drop from the rotarod in $\sec \pm \mathrm{SE}$ and analyzed using Student's two-tailed t-test for comparisons by day using GraphPad Prism..

TreadScan ${ }^{\bullet}$ Gait Analysis System Abnormalities in gait in male SNAP25 $\Delta 3$ homozygotes or wild-type littermate controls were assessed with the TreadScan ${ }^{\bullet}$ system (CleverSys, Inc., Reston, VA) ${ }^{53}$. Animals were placed on a transparent treadmill and made to run at treadmill speeds $(\mathrm{mm} / \mathrm{sec})$ of 120 or 160 , while video footage of the animal's paws was recorded. The animals were tested starting from the lowest to highest speed with a 20 minute interval between each test. Video footage was analyzed for the position of each paw utilizing the Treadscan software suite to assess any abnormalities in gait. Data were represented as the mean $\pm \mathrm{SE}$ for the following parameters: brake duration (msec), stance duration 
(msec), gait angle $\left({ }^{\circ}\right)$, track width $(\mathrm{mm})$, stride frequency $(\mathrm{Hz})$, stride length $(\mathrm{mm}), \%$ stance, stride duration (msec), swing duration (msec), propel duration (msec), and run speed ( $\mathrm{mm} / \mathrm{s})$ and analyzed using Student's two-tailed t-test using GraphPad Prism.

Light-dark exploration: Anxiety responses were assessed in age-matched WT or SNAP25 33 homozygote male mice in a plastic cubic light-dark chamber $20 \mathrm{~cm}$ in length ${ }^{54}$. A black opaque Plexiglas insert was utilized to selectively create darkness in half of the chamber. Animals were placed individually in each chamber for 5 minutes, with animal movement being recorded by the breaking of photobeams emitted by infrared photocells in each chamber. Time spent in the light side of the chamber (sec), number of transitions made by each mouse between the light and dark sides of the chamber, and distance traveled in the light and the dark sides of the testing chamber $(\mathrm{cm})$ were recorded. Data are represented as means \pm SEM and were analyzed by Student's two-tailed t-test using GraphPad Prism.

Forced Swim Task: Age-matched littermates 16-17-week old WT $(\mathrm{n}=14)$ or SNAP25 $\Delta 3(\mathrm{n}=17)$ homozygote male mice were tested in forced swim paradigm ${ }^{55}$. The depth of the water was such that the mice tail does not touch the bottom, but also prevents them from escaping the apparatus. For testing, each mouse was placed in the cylinder for 6 mins, and the latency to immobility and the immobility time (i.e. the time during which mice made only the small movements necessary to keep their heads above water) was scored. Only the data scored during the last 4 min were analyzed. Data are represented as means \pm SEM and were analyzed by Student's two-tailed t-test using GraphPad Prism.

Morris Water Maze Mice were trained to locate a hidden platform in a standard fixed platform memory acquisition task, in which the platform remained in a constant position, see methods ${ }^{96,97}$. This acquisition phase lasted for six sessions, each of which consisted of four trials separated by approximately $10 \mathrm{~min}$. Four points along the perimeter of the maze, served as starting points where the mice were released, facing the wall of the tank, at the beginning of each trial (the order of the starting points were determined 
randomly, except that each starting point was used only once each session). After a mouse located the platform, it was allowed to remain there for $30 \mathrm{~s}$ before being removed from the tank. If a mouse failed to locate the platform within $60 \mathrm{~s}$, it was manually guided to it and again allowed to remain on the platform for $30 \mathrm{~s}$. Data are represented as means \pm SEM and were analyzed by Two-way ANOVA using GraphPad Prism.

BNST Electrophysiological analyses Adult mice (>8 weeks) were single housed in the institutional vivarium prior to experiments. Food and water were available ad libitum. All procedures were approved by the Animal Care and Use Committee at Vanderbilt University. Mice were transported from the animal colony to the laboratory and allowed to acclimate in a sound-attenuation chamber for $>1$ hour before the experiment. They were then anesthetized with isoflurane until unresponsive to foot pinch. The mice were transcardially perfused with ice-cold sucrose-substituted artificial cerebrospinal fluid (ACSF) (in mM: 194 sucrose, $20 \mathrm{NaCl}, 4.4 \mathrm{KCl}, 2 \mathrm{CaCl}_{2}, 1 \mathrm{MgCl}_{2}, 1.2 \mathrm{NaH}_{2} \mathrm{PO}_{4}, 10.0$ glucose, and $26.0 \mathrm{NaHCO}_{3}$ ) saturated with $95 \% \mathrm{O}_{2} / 5 \% \mathrm{CO}_{2}$. They were then decapitated and the brain was quickly removed and placed in ice-cold sucrose ACSF. Slices $300 \mu \mathrm{m}$ thick containing the bed nucleus of the stria terminalis (bregma +0.26 to $+0.14 \mathrm{~mm}$ ) were prepared using a Tissue Slicer (Leica). After dissection, slices were transferred to a holding chamber containing heated $\left(\sim 29^{\circ} \mathrm{C}\right)$ oxygenated $\left(95 \% \quad \mathrm{O}_{2} / 5 \% \mathrm{CO}_{2}\right)$ ACSF (in mM: $124 \mathrm{NaCl}, 4.4 \mathrm{KCl}, 2 \mathrm{CaCl}_{2}, 1.2 \mathrm{MgSO}_{4}, 1 \mathrm{NaH}_{2} \mathrm{PO}_{4}, 10.0$ glucose, $26.0 \mathrm{NaHCO}_{3}$; pH 7.2-7.4; 295305 mOsm). Recording electrodes (0.5-2 M 2 ) were pulled on a Flaming-Brown Micropipette Puller (Sutter Instruments) using thin-walled borosilicate glass capillaries. Excitatory field potentials were evoked by local fiber stimulation with bipolar nichrome electrodes. Electrical stimulation (1-15 V with 5 ms duration) was applied at $0.0167 \mathrm{~Hz}$. Recording electrodes were filled with ACSF and all experiments were done in the presence of $25 \mu \mathrm{M}$ picrotoxin to isolate fast excitatory transmission. Signals were acquired via a Multiclamp 700B amplifier (Axon Instruments), and digitized and analyzed via pClamp 10.2 software (Axon Instruments). The fiber volley potential (N1) was monitored continuously throughout the duration of the experiment. Experiments in which N1 changed by $20 \%$ in either direction 
were not included in subsequent analysis. Experiments were analyzed by measuring peak amplitudes of the N1 and N2 (synaptic potential) relative to the amplitude with no stimulation. This measure was then normalized to the last ten minutes of the baseline period (10-20 minutes). Welch's t-test was used to compare the average amplitude over the last 20 minutes of the experiment relative to baseline across the two genotypes.

Subiculum Electrophysiological analyses: All procedures were approved by the Animal Care and Use Committee at Vanderbilt University and at the University of Illinois at Chicago. Male and female adult mice ( $>8$ weeks) were obtained from the institutional vivarium prior to experiments, where food and water were available ad libitum. Mice were transported from the animal colony to the laboratory and allowed to acclimate for $>1$ hour before the experiment. They were then anesthetized with isoflurane until unresponsive to foot pinch. The mice were decapitated and the brain was quickly removed and placed in ice-cold sucrose-substituted artificial cerebrospinal fluid (ACSF) (in M: 11 D-Glucose, 234 sucrose, 2.5 $\mathrm{KCl}, 1.25 \mathrm{NaH}_{2} \mathrm{PO}_{4}, 10 \mathrm{MgSO}_{4}$, and $26 \mathrm{NaHCO}_{3}$; in $\mathrm{mM}$ : $0.5 \mathrm{CaCl}_{2}$,) saturated with $95 \% \mathrm{O}_{2} / 5 \% \mathrm{CO}_{2}$. Slices $300 \mu \mathrm{m}$ thick containing the hippocampus and subiculum were prepared using a Tissue Slicer (Leica VT1200S). After dissection, slices were transferred to a holding chamber containing oxygenated $\left(95 \% \mathrm{O}_{2} / 5 \% \mathrm{CO}_{2}\right.$ ) ACSF (in mM: $123 \mathrm{NaCl}, 26 \mathrm{NaHCO}_{3}, 3 \mathrm{KCl}, 1.25 \mathrm{NaH}_{2} \mathrm{PO}_{4}, 11$ D-Glucose; $2 \mathrm{CaCl}_{2}$, $\left.1 \mathrm{MgCl}_{2} ; \mathrm{pH} 7.2-7.4 ; 295-305 \mathrm{mOsm}\right)$ for 45 minutes in a heated $\left(\sim 30^{\circ} \mathrm{C}\right)$ water bath then moved to room temperature for storage. Recording electrodes (3-5 M $\Omega$ filled with ACSF) were pulled on a FlamingBrown Micropipette Puller (Sutter Instruments) using standard-walled borosilicate glass capillaries. Excitatory field potentials were evoked by local fiber stimulation with bipolar twisted insulated NiChrome electrodes in an interface chamber (Warner, BSC-BUW) heated to $\sim 30^{\circ} \mathrm{C}$. Electrical stimulation $(200 \mu$ s at 30 to $60 \mu \mathrm{A}$ range) was applied every 30 seconds. All experiments were done in the presence of $10 \mu \mathrm{M}$ bicuculline to black $\mathrm{GABA}_{\mathrm{A}}$ receptors and $50 \mu \mathrm{M}$ D-2 amino-5phosphonopentanoate (D-AP5) to block NMDA receptors to isolate AMPAR-mediated EPSPs. Signals were acquired via an Axoclamp 2B amplifier (Axon Instruments) amplified $100 \mathrm{x}$ and band pass 
filtered $(0.1$ to $5 \mathrm{KHz})$, and digitized and analyzed via AxographX version 1.6.5 software. Experiments were analyzed by measuring the initial slope of the excitatory postsynaptic potential and then normalized to the last ten minutes of the baseline period (20 minutes). Student's t-test was used to compare the average slope over the last 10 minutes of each dose of CP93129 (0, 50, 100, 200, 400, 800, and $100 \mathrm{nM})$ or baclofen $(0,0.5,1,2,5$, and $10 \mu \mathrm{M})$ concentrations relative to baseline across the wild-type and SNAP25 $\Delta 3$ genotypes.

\section{FIGURE LEGENDS}

Figure 1. Creation of the SNAP25 $\Delta 3$ mouse via CRISPR-Cas9. Graphical representation of region on mouse chromosome 2 targeted by the sgRNA (upper panel) cloned into px330 and the subsequent region after homology-directed repair (lower panel) containing the G204* mutation and cloning site. B. Agarose gel electrophoresis of PCR products generated from reactions containing two different 5' primers utilized to genotype WT, heterozygote, and homozygote SNAP25 33 littermate animals. The WT 5' primer corresponds to the WT region on mouse chromosome 2, whereas the SNAP25 33 primer corresponds to the region containing the G204* mutation. C1. Gross morphology of WT and SNAP25 33 homozygotes and (C2) growth curves showing the increase in body mass in WT $(n=12-18)$ and SNAP25 $3(n=12-21)$ homozygotes over the first 60 weeks of life of several noncontinuous cohorts. D. Immunoblot analysis of presynaptic proteins expressed within synaptosomal ${ }^{100,94,101}$ fractions (all except for syt I and VII, and VAMP2) or whole mouse brain lysate (syt I and VII, and VAMP2). A decrease in cysteine string protein $(\mathrm{CSP})$ was found in the presynaptic fraction of SNAP25 $\Delta 3$ synaptosomes $(\mathrm{P}<0.03$, $\mathrm{N}=12$ ). No statistically significant difference was found in other proteins. E. Immunofluorescence imaging of GABAergic (VGAT) and glutamatergic (vGlut2) immunoreactive appositions ${ }^{46}$ within hippocampal slices taken from adult WT or SNAP25 $\Delta 3$ homozygotes $(n=4)$. Anti-HuC/D was utilized as a pan-neuronal marker (Hu proteins are mammalian embryonic lethal abnormal visual system (ELAV)like neuronal RNA-binding proteins). 
Figure 2. SNAP25 $\Delta 3$ impairs G $\beta \gamma$ competition with synaptotagmin I and inhibition of calciumsynaptotagmin I-mediated liposome fusion. A. Syt1 competition with G $\beta \gamma$ at t-SNARE complexes in lipid bilayers. (A1) Schematic of the imaging system. A lipid bilayer consisting of 55\% PC/15\%PE/29\%PS /1\% DiD harboring t-SNARE complexes was fused to a glass coverslip and imaged using TIRF illumination from a 1.45 NA 60x lens through a laser TIRF illuminator. $1 \mu \mathrm{M}$ Ca-AF-syt1 was applied over the bilayer (100 $\mu \mathrm{M} \mathrm{Ca}^{2+}$ ). (A2) Graph shows $\mathrm{G} \beta_{1} \gamma_{1}$ concentration dependence of the change in anisotropy produced by AF-syt I binding to WT (blue) or SNAP25 $\Delta 3$ (red)-containing tSNAREs embedded in the lipid membranes. The ability of $\mathrm{G} \beta_{1} \gamma_{1}$ to displace AF-syt1 from SNAP $25 \Delta 3 \mathrm{t}$ SNAREs was reduced to $47 \pm 13 \%$ of its displacement of AF-syt1 from WT SNAP-25, as measured by change in anisotropy $(\mathrm{n}=5, \mathrm{p}=0.019)$.. AF-sytI displacement from WT t-SNAREs had an $\mathrm{IC}_{50}$ of 502 nM (95\% CI: 150nM). B. Traces of lipid mixing experiments in which liposomes containing tSNAREcomplexes made with SNAP25WT or SNAP25 43 are incubated with liposomes containing VAMP2 and a FRET pair of NBD-PE and rhodamine-PE in addition to $10 \mu \mathrm{M}$ sytI and G $\beta_{1} \gamma_{1}$. At $\mathrm{t}=20$ min, $1 \mathrm{mM} \mathrm{CaCl} 2$ is added. C1. Bar graph of maximum fluorescence values : $2 \mu \mathrm{M} \mathrm{G} \beta \gamma$ significantly inhibits lipid mixing with liposomes containing t-SNAREs made with SNAP25WT ( $\mathrm{p}=0.0083$ ) but not SNAP25 $\Delta 3(\mathrm{p}=0.71)$, while $6 \mu \mathrm{M}$ G $\beta \gamma$ inhibits significantly less in SNAP25 $\Delta 3$ liposomes than SNAP25WT $(\mathrm{p}=0.0461)$. C2. Table of significance values for lipid mixing experiments (Student's twotailed t-test). Experiments were repeated 6-8 times for 6-10 technical replicates.

Figure 3. SNAP25 $\Delta 3$ mutant mice have impaired motor coordination and altered gait. A1. Mutant mice have normal locomotor behavior in the open chamber. Plot of distance traveled in five-minute intervals in a brightly illuminated open field for age-matched littermate SNAP25 $\Delta 3$ homozygotes (red line) $(\mathrm{n}=14)$ and WT (blue line) $(\mathrm{n}=15) 15$ weeks of age. A2. Total distance traveled $(\mathrm{p}=0.8088)$ and number of rearing movements $(\mathrm{p}=0.0796)$ made are plotted below for each genotype. B. Plot of latency 
to drop from an accelerating, rotating beam for 16 week old male WT $(n=15)$ and homozygotes SNAP25 $33(n=14)$ in the rotarod paradigm. Animals were tested daily for three consecutive days. Agematched littermate SNAP25 $\Delta 3$ homozygotes had a significantly reduced latency to drop on the second and third day of testing compared to wild-type controls $(* *, p<0.01$, ***, p<0.001, Student's two-tailed ttest). C. Brake duration for each paw as measured by TreadScan ${ }^{\bullet}$ gait analysis in which the paws of a running male age-matched WT or SNAP $25 \Delta 3$ homozygote are imaged by a camera located beneath a transparent treadmill moving at a speed of $160 \mathrm{~mm} / \mathrm{s}$. SNAP25 $\Delta 3$ homozygotes had significantly greater brake duration than wild-type littermates in each paw $\left({ }^{*} \mathrm{p}<0.05\right)$ except for the rear left paw $(\mathrm{p}=0.94$, D. Stance duration for each paw as measured by $\operatorname{TreadScan}^{\circ}$ gait analysis in which the paws of a running age-matched WT or SNAP25 33 homozygote were imaged by a camera located beneath a transparent treadmill moving at a speed of $160 \mathrm{~mm} / \mathrm{s}$. SNAP25 $\Delta 3$ homozygotes had significantly greater stance duration than wild-type littermates in each paw $(* \mathrm{p}<0.05)$.

Figure 4. SNAP25 $\Delta 3$ mutant mice showed altered affect and supraspinal nociception. A. SNAP25 $\Delta 3$ animals show greater immobility in the forced swim paradigm. A1. Bar graph shows the time spent immobile subsequent to immersion for 16-17-week old littermate male WT $(n=14)$ or SNAP25 $\Delta 3(n=17)$ homozygotes. Immobility time was significantly greater for SNAP25 $\Delta 3$ than WT littermates $(* * \mathrm{p}<0.01$, Student's two-tailed t-test) A2. Bar graph showing the latency to immobility subsequent to immersion for littermate male WT or SNAP25 $\Delta 3$ homozygotes in the forced swim paradigm. Latency time before immobility was significantly lower for SNAP25 $\Delta 3$ than WT littermates $(* * p<0.01)$ B. SNAP25 23 animals have impaired nociception. B1. Bar graph showing latency required for 20 week old littermate male WT $(n=14)$ or SNAP25 $33(n=17)$ homozygotes to respond to supraspinal thermal pain in the hot plate paradigm, in which animals are placed on a plate heated to $55^{\circ} \mathrm{C}$ and the time required to produce a paw movement is measured. Latency time was significantly greater for 
SNAP25 $\triangle 3$ than WT littermates $(* * \mathrm{p}<0.01$, Student's two-tailed t-test). B2. Bar graph showing latency required for 21 -week old littermate male WT $(n=14)$ or SNAP $25 \Delta 3$ homozygotes $(n=17)$ to respond to spinal thermal nociception in in the tail flick paradigm, in which mouse tails are immersed in a hot water bath heated to $50^{\circ}$ or $55^{\circ} \mathrm{C}$ and the time required for tail movement is recorded. No differences were detected between littermate SNAP25 $\triangle 3$ and WT $(\mathrm{p}=0.29$ and 0.53 respectively, Student's two-tailed ttest).

Figure 5. SNAP25 $\Delta 3$ mice have altered stress responses and impaired $\alpha_{2 \mathrm{a}}$ heteroreceptor signaling in the BNST. A. Bar graph of significant changes in rectal temperature subsequent to handling in singly-housed littermate male WT $(n=17)$ and SNAP25 $\Delta 3$ homozygotes $(n=21)$ of 13-14 weeks of age $(* * * * \mathrm{p}<0.00001)$. B. Diagram showing synaptology of $\alpha_{2 \mathrm{a}}$ heteroreceptor inhibitory signaling on excitatory parabrachial inputs on the bed nuclei of the stria terminalis. C. Example field potential from coronal brain slices containing the dorsal BNST illustrating the N1 and N2 downward deflections. D. Normalized change in the N2 component of excitatory postsynaptic potentials recorded in the BNSTcontaining slices taken from WT (in blue) and SNAP25 33 homozygote male mice (in red) at an age of $>8$ weeks. $1 \mathrm{uM}$ guanfacine was administered from $\mathrm{t}=20 \mathrm{~min}$ to $\mathrm{t}=40 \mathrm{~min}$. E. Bar graph showing relative amplitude of the $\mathrm{N} 2$ component of EPSPs at $\mathrm{t}=80 \mathrm{~min}$ as a fraction of the amplitude prior to the administration of guanfacine at $\mathrm{t}=10-20 \mathrm{~min}$. Guanfacine reduced the N2 component of the EPSP significantly less in slices from SNAP25 $\Delta 3$ homozygotes than WT $(* * * p<0.001$, Mann-Whitney u-test) F. Normalized change in the N2 component of excitatory postsynaptic potentials recorded in the BNSTcontaining slices taken from WT and SNAP25 $\Delta 3$ homozygotes at an age of 8-14 weeks. 10uM baclofen was administered from $\mathrm{t}=20 \mathrm{~min}$ to $\mathrm{t}=40 \mathrm{~min}$. G. Bar graph showing relative amplitude of the N2 component of EPSPs at $\mathrm{t}=80 \mathrm{~min}$ as a fraction of the amplitude prior to the administration of baclofen at $\mathrm{t}=10$ - 20min. No significant differences were observed between genotypes $(\mathrm{p}=0.92)$. 
Figure 6. SNAP25 $\Delta 3$ homozygotes have impaired $G_{\mathrm{i} / 0}$-coupled GPCR signaling in CA1/subiculuar hippocampal neurons and show impaired hippocampal spatial learning. A. Diagram of hippocampal field recording paradigm. Stimulation via bipolar electrodes over the CA1-subicular pathway evoked field EPSPs recorded in basal dendrites of subicular pyramidal neurons in AP5 (50 $\mu \mathrm{M})$ and bicuculline $(5 \mu \mathrm{M})$ to isolate AMPAR-mediated responses. B. Traces from CA1-subicular recordings in WT (B1) and SNAP25 3 (B2) slices at 0 and $400 \mathrm{nM} \mathrm{CP93129.} \mathrm{B3.} \mathrm{Dose} \mathrm{response} \mathrm{of} \mathrm{the} \mathrm{effect} \mathrm{of} \mathrm{CP93129} \mathrm{on} \mathrm{the}$ AMPA component of these field EPSPs from 6-week old littermate WT (in blue) or SNAP25 3 homozygotes (in red). Amplitudes were normalized to the control response. CP93129 was significantly more potent in WT than SNAP25 $\Delta 3(* * \mathrm{p}=0.0068,400 \mathrm{nM} ; * * \mathrm{p}=0.0035,800 \mathrm{nM} ; * * * \mathrm{p}=0.001$, $1600 \mathrm{nM}$; Student's t-test). C. Traces from field recordings in wild-type (C1) and SNAP25 3 (C2) slices at 0 and $1.0 \mu \mathrm{M}$ baclofen. C3. Dose-response of the effect of baclofen on field EPSPs recorded in the WT or SNAP25 $\triangle 3$ hippocampal slices. No significant differences were detected by genotype. D. Comparison between age-matched littermate WT and SNAP25 $\Delta 3$ homozygotes in the acquisition of the Morris Water Maze Task over a 5 day trial period by genotype $(\mathrm{p}<0.05)$ and time $(\mathrm{p}<0.0001)$.

Figure 7 Synergy between $5-\mathrm{HT}_{1 \mathrm{~B}}$ and $\mathrm{GABA}_{\mathrm{B}}$ at the CA1/subicular synapse. A. Schematic of targets within the presynaptic terminal for $\mathrm{G}_{\mathrm{i} / \mathrm{o}}$-coupled GPCRs. In CA1 terminals, 5-HT ${ }_{1 b}$ Rs release G $\beta \gamma$ to bind SNAREs and $\mathrm{GABA}_{\mathrm{B}}$ receptors release $\mathrm{G} \beta \gamma$ to inhibit $\mathrm{Ca}^{2+}$ channels. Synergistic effects of 5$\mathrm{HT}_{1 \mathrm{~b}} \mathrm{Rs}$ and $\mathrm{GABA}_{\mathrm{B}} \mathrm{R}_{\mathrm{s}}$ B. Stimulation of the CA1-subicular pathway evoked whole cell recorded EPSCs in subicular pyramidal neurons. During repetitive stimulation, CP93129 (400 nM, blue) substantially inhibited the first response, but response amplitudes recovered during the stimulus train. The ratio of inhibition of the $1^{\text {st }}$ vs. the $5^{\text {th }}$ response was $4.6 \pm 0.8$. Baclofen $(1 \mu \mathrm{M}$, green $)$ uniformly inhibited EPSCs throughout the stimulus train; the ratio was $1.1 \pm 0.2$. Addition of CP93129 + baclofen, pink) substantially inhibited responses throughout the stimulus train $(* * * \mathrm{p}=0.0002)$. C.. Quantitation of the effects of CP93129 (400 nM) alone and after addition of baclofen $(1 \mu \mathrm{M})$. 


\section{Supplementary Tables and Figures.}

Figure S1. Table of neurobehavioral parameters screened in Modified Irwin Neurological Test

Battery. A1. Aggregate scores of autonomic component of Irwin neurobehavioral screen conducted in 14-15 week old age-matched WT and SNAP25 $\Delta 3$ homozygote male mice. $(\mathrm{n}=17-21 ; * * * \mathrm{p}<0.001) . \quad$ A2. Aggregate scores of somatomotor component of Irwin neurobehavioral screen conducted in male WT and SNAP25 33 homozygotes $(\mathrm{n}=17-21, * * * * \mathrm{p}<0.0001)$. B. The effects of WT $(\mathrm{n}=17)$ were compared to littermate SNAP25 3 homozygotes $(n=21)$ on the autonomic nervous system and somatomotor function. The mean scores for each parameter are classified as follows:-,=no effect; $(+), 0.01-0.25 ;+, 0.251-0.50$; ,$++ 0.51-1.0 ;+++, 1.01-1.50 ;++++, 1.51-2.0 ; * * \mathrm{p}<0.01$ vs. vehicle (Student's two-tailed t-test).

Figure S2. SNAP25 $\Delta 3$ homozygotes do not display abnormalities in unstressed motor function. A. Plot of distance traveled in five-minute intervals in a dark open field for littermate WT and SNAP $25 \Delta 3$ homozygotes 16 weeks of age. Total distance traveled and number of rearing movements are plotted below. No significant differences by genotype were seen in this paradigm as measured by two-way ANOVA.

Figure S3. Additional gait parameters studied in the SNAP25 $\Delta 3$ homozygote. A-I: Tabulated parameters for each paw as measured by TreadScan ${ }^{\circ}$ gait analysis in which the paws of a running male WT or SNAP25 $\Delta 3$ homozygote are imaged by a camera located beneath a transparent treadmill moving at a speed of 120 or $160 \mathrm{~mm} / \mathrm{s}$. Parameters, such as gait angle, track width, stride frequency, stride length, $\%$ stance, stride duration, swing duration, propel duration and run speed exhibited no or very modest differences between WT and SNAP25 33 homozygotes $(*, p<0.05$ Student's two-tailed t-test). Animal cohort sizes were identical to Figure 4.). 
Figure S4: SNAP25 $\Delta 3$ homozygotes do not display elevated anxiety in the absence of external

stressors. A-B. Bar graphs showing time spent by 24-week old littermate male WT $(n=14)$ or SNAP25 $\triangle 3$ homozygotes $(n=16)$ in each side of a bipartite chamber in which one half was darkened through the use of a Plexiglass divider. Data were represented as time spent in the light side of the chamber (sec), number of transitions made by each mouse between the light and dark sides of the chamber, and distance traveled in the light and the dark sides of the testing chamber $(\mathrm{cm})$ as denoted by the number of infrared beam breaks within the apparatus in dark or light portion of the testing apparatus. No significant differences were detected in time spent in each side of the chamber $(\mathrm{p}=0.5209)$ or number of transitions made $(\mathrm{p}=0.2601)$.

\section{ACKNOWLEDGEMENTS}

The work in this paper was supported by R01EY010291; R01MH101679 and R01DK109394 to HEH; R01MH 08487 to STA; R01DA042475 and F30DA042501 to DGW. We thank Jennifer Skelton and the Vanderbilt Transgenic Mouse and Embryonic Stem Cell Resource (supported by NIH grants CCSG CA68485 and DRTC DK020593) for assistance in the creation of the SNAP25 $\Delta 3$ mouse. We thank the Vanderbilt High-throughput Screening Core for providing instrumentation for lipid mixing experiments. We thank John Allison, Ph.D and the Vanderbilt Murine Neurobehavioral Core for providing training and instrumentation for the behavioral studies conducted upon the SNAP25 $\Delta 3$ mouse. We thank Bob Matthews Ph.D and the Vanderbilt Cell Imaging Shared Resource (supported by NIH grants CA68485, DK20593, DK58404, DK59637, and Ey08126) for training and instrumentation in microscopy. We thank Mark Fulton and Kayla Jo Temple for assistance in liposome production, and the laboratory of Feng Zhang, Ph.D (Massachusetts Institute of Technology) and Addgene for the gift of the px330 plasmid.

\section{AUTHOR CONTRIBUTIONS:}

Conceptualization, Z. Z., D.P.M., D.G.W., S.A., C.K.J.,., and H.E.H. Formal Analysis, Z. Z., A. D. T. G., L. J. B., YY. Y., N. A. H., and S. A. Methodology, Z. Z., A.D.T.G., YY.Y., D.G.W., S.A., C.K.J., and 
H.E.H. Investigation, Z. Z., A.D.T.G., L.J.B., B.P., E.C., N.A.H., M.R.D., YY.Y. and S. A. Writing-

Original Draft, Z. Z., A.D.T.G., L.J.B., N.A.H., YY.Y., D.G.W., S.A., C.K.J., and H.E.H. Writing-

Review and Editing, Z. Z., A.D.T.G., L.J.B., N.A.H., YY.Y., D.G.W., S.A., C.K.J., and H.E.H. Resources, Z. Z., A.D.T.G., K.H., L.J.B., and D.P.M. Funding Acquisition, H.E.H. Supervision, D.G.W., S.A., C.K.J., and H.E.H.

\section{DECLARATION OF INTERESTS}

The authors declare no competing interests.

\section{REFERENCES}

1 Leenders, A. G. M. \& Sheng, Z.-H. Modulation of neurotransmitter release by the second messenger-activated protein kinases: Implications for presynaptic plasticity. Pharmacology \& therapeutics 105, 69-84, doi:10.1016/j.pharmthera.2004.10.012 (2005).

2 Dunlap, K. F., GD. Neurotransmitters decrease the calcium component of sensory neurone action potentials. Nature 276, 837-839 (1978).

3 Bean, B. P. Neurotransmitter inhibition of neuronal calcium currents by changes in channel voltage dependence. Nature 340, 153-156 (1989).

4 Miller, R. J. Presynaptic receptors. Annual Reviews in Pharmacology and Toxicology 38, 201-227 (1998).

5 Herlitze, S., D.E. Garcia, K. Mackie, B. Hille, T. Scheuer, and W.A. Catterall Modulation of Ca2+ channels by G-protein bg subunits. Nature 380, 258-262 (1996).

$6 \quad$ Ikeda, S. R. Voltage-dependent modulation of N-type calcium channels by G-protein beta gamma subunits. Nature 380, 255-258 (1996).

7 De Waard, M. et al. Direct binding of G-protein betagamma complex to voltage-dependent calcium channels [see comments]. Nature 385, 446-450 (1997).

8 Zhang, J. F., Ellinor, P. T., Aldrich, R. W. \& Tsien, R. W. Multiple structural elements in voltage-dependent $\mathrm{Ca} 2+$ channels support their inhibition by $\mathrm{G}$ proteins. Neuron 17, 991-1003 (1996).

9 Zamponi, G. W., Bourinet, E., Nelson, D., Nargeot, J. \& Snutch, T. P. Crosstalk between G proteins and protein kinase $\mathrm{C}$ mediated by the calcium channel alpha1 subunit. Nature. 385, 442446. (1997).

10 Dolphin, A. C. Mechanisms of modulation of voltage-dependent calcium channels by G proteins. J Physiol 506 ( Pt 1), 3-11 (1998).

11 Logothetis, D. E., Kurachi, Y., Galper, J., Neer, E. J. \& Clapham, D. E. The betagamma subunits of GTP-binding proteins activate the muscarinic K+ channel in heart. Nature 325, 321-326 (1987).

12 Reuveny, E. et al. Activation of the cloned muscarinic potassium channel by G protein [beta][gamma] subunits. Nature 370, 143-146 (1994).

13 Wickman, K. D. et al. Recombinant G-protein [beta][gamma]-subunits activate the muscarinicgated atrial potassium channel. Nature 368, 255-257 (1994). 
14 Wells, C. A. et al. G $\beta \gamma$ Inhibits Exocytosis via Interaction with Critical Residues on Soluble NEthylmaleimide-Sensitive Factor Attachment Protein-25. Molecular Pharmacology 82, 11361149, doi:10.1124/mol.112.080507 (2012).

15 Blackmer, T. et al. G protein betagamma subunit-mediated presynaptic inhibition: regulation of exocytotic fusion downstream of Ca2+ entry. Science 292, 293-297. (2001).

16 Blackmer, T. et al. G protein betagamma directly regulates SNARE protein fusion machinery for secretory granule exocytosis. Nat Neurosci 8, 421-425 (2005).

17 Gerachshenko, T. et al. Gbetagamma acts at the C terminus of SNAP-25 to mediate presynaptic inhibition. Nat Neurosci 8, 597-605 (2005).

18 Chen, X. K. et al. Activation of GPCRs modulates quantal size in chromaffin cells through G(betagamma) and PKC. Nat Neurosci 8, 1160-1168 (2005).

19 Delaney, A. J., Crane, J. W. \& Sah, P. Noradrenaline Modulates Transmission at a Central Synapse by a Presynaptic Mechanism. Neuron 56, 880-892, doi:https://doi.org/10.1016/j.neuron.2007.10.022 (2007).

20 Glitsch, M. Selective Inhibition of Spontaneous But Not Ca2+-Dependent Release Machinery by Presynaptic Group II mGluRs in Rat Cerebellar Slices. Journal of Neurophysiology 96, 86 (2006).

21 Yoon, E. J., T. Gerachshenko, B.D. Spiegelberg, S. Alford, and H.E. Hamm. Gbg interferes with $\mathrm{Ca} 2+$-dependent binding of synaptotagmin to the soluble N-ethylmaleimide-sensitive factor attachment protein receptor (SNARE) complex. Mol. Pharmacol. 72, 1210-1219 (2007).

22 Yoon, E. J., H.E. Hamm, and K.P.M. Currie. G protein bg subunits modulate the number and nature of exocytotic fusion events in adrenal chromaffin cells independent of calcium entry. $J$ Neurophysiol 100, 2929-2939. (2008).

23 Iremonger, K. J. \& Bains, J. S. Retrograde Opioid Signaling Regulates Glutamatergic Transmission in the Hypothalamus. The Journal of Neuroscience 29, 7349 (2009).

24 Zhao, Y., Fang, Q., Straub, S. G., Lindau, M. \& Sharp, G. W. G. Noradrenaline inhibits exocytosis via the $\mathrm{G}$ protein bg subunit and refilling of the readily releasable granule pool via the $\mathrm{a}_{\mathrm{i}} 1 / 2$ subunit. The Journal of Physiology 588, 3485-3498, doi:10.1113/jphysiol.2010.190090 (2010).

25 Hamid, E. et al. Modulation of Neurotransmission by GPCRs Is Dependent upon the Microarchitecture of the Primed Vesicle Complex. The Journal of Neuroscience 34, 260-274, doi:10.1523/JNEUROSCI.3633-12.2014 (2014).

26 Zurawski, Z., Rodriguez, S., Hyde, K., Alford, S. \& Hamm, H. E. G $\beta \gamma$ Binds to the Extreme C Terminus of SNAP25 to Mediate the Action of Gi/o-Coupled G Protein-Coupled Receptors. Molecular Pharmacology 89, 75-83 (2016).

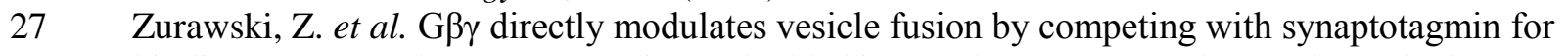
binding to neuronal SNARE proteins embedded in membranes. Journal of Biological Chemistry 292, 12165-12177 doi:doi:10.1074/jbc.M116.773523 (2017).

28 Van Hook, M. J. et al. A presynaptic group III mGluR recruits G $\beta \gamma /$ SNARE interactions to inhibit synaptic transmission by cone photoreceptors in the vertebrate retina. The Journal of Neuroscience, doi:10.1523/jneurosci.2948-16.2017 (2017).

29 Betke KM, W. C., Hamm HE. GPCR mediated regulation of synaptic transmission. Prog Neurobiol. 3 (2012).

30 Dolphin, A. C. \& Scott, R. H. Calcium channel currents and their inhibition by (-)-baclofen in rat sensory neurones: modulation by guanine nucleotides. Journal of Physiology, London 386, 1-17 (1987).

31 Wu, L. G. \& Saggau, P. Adenosine inhibits evoked synaptic transmission primarily by reducing presynaptic calcium influx in area CA1 of hippocampus. Neuron 12, 1139-1148 (1994).

32 Tedford, H. W. \& Zamponi, G. W. Direct G Protein Modulation of Ca\&lt;sub\&gt;v\&lt;/sub\&gt;2 Calcium Channels. Pharmacological Reviews 58, 837 (2006). 
33 Proft, J. \& Weiss, N. G Protein Regulation of Neuronal Calcium Channels: Back to the Future. Molecular Pharmacology 87, 890 (2015).

34 Augustine, G. J. \& Charlton, M. P. Calcium dependence of presynaptic calcium current and postsynaptic response at the squid giant synapse. The Journal of Physiology 381, 619-640 (1986). Dodge, F. A., Jr. \& Rahamimoff, R. Co-operative action a calcium ions in transmitter release at the neuromuscular junction. J Physiol 193, 419-432 (1967).

36 Mizutani, H., Hori, T. \& Takahashi, T. 5-HT1B receptor-mediated presynaptic inhibition at the calyx of Held of immature rats. European Journal of Neuroscience 24, 1946-1954, doi:10.1111/j.1460-9568.2006.05063.x (2006).

37 Takahashi, T., Forsythe, I. D., Tsujimoto, T., Barnes-Davies, M. \& Onodera, K. Presynaptic Calcium Current Modulation by a Metabotropic Glutamate Receptor. Science 274, 594 (1996). Scanziani, M., Capogna, M., Gähwiler, B. H. \& Thompson, S. M. Presynaptic inhibition of miniature excitatory synaptic currents by baclofen and adenosine in the hippocampus. Neuron $\mathbf{9}$, 919-927, doi:http://dx.doi.org/10.1016/0896-6273(92)90244-8 (1992).

39 Scanziani, M., Gahwiler, B. H. \& Thompsom, S. M. Presynaptic inhibition of excitatory synaptic transmission by muscarinic and metabotropic glutamate receptor activation in the hippcampus: are Ca2+ channels involved? Neuropharmacology 34, 1549-1557 (1995).

40 Silinsky, E. M. On the mechanism by which adenosine recptor activation inhibits the release of acetylcholine from motor nerve endings. Journal of Physiology 346, 243-256 (1984).

41 Silinsky, E. M. \& Solsona, C. S. Calcium currents at motor nerve endings: absence of effects of adenosine receptors agonists in the frog. Journal of Physiology, London 457, 315-328 (1992).

42 Luini, A. \& De Matteis, M. A. Evidence that the receptor-linked G protein inhibits exocytosis by a post-second messenger mechanism in AtT-20 cells. Journal of Neurochemistry 54, 30-38 (1990).

43 Scholz, K. P. \& Miller, R. J. Inhibition of quantal transmitter release in the absence of calcium influx by a $\mathrm{G}$ protein linked adenosine receptor at hippocampal synapses. Neuron 8, 1139-1150 (1992).

44 Dittman, J. S. \& Regehr, W. G. Contributions of calcium-dependent and calcium-independent mechanisms to presynaptic inhibition at a cerebellar synapse. The Journal of Neuroscience 16, 1623 (1996).

45 Criado, M., Gil, A., Viniegra, S. \& Gutiérrez, L. M. A single amino acid near the C terminus of the synaptosomeassociated protein of $25 \mathrm{kDa}$ (SNAP-25) is essential for exocytosis in chromaffin cells. Proceedings of the National Academy of Sciences 96, 7256-7261, doi:10.1073/pnas.96.13.7256 (1999).

46 Bouyer, K. \& Simerly, R. B. Neonatal Leptin Exposure Specifies Innervation of Presympathetic Hypothalamic Neurons and Improves the Metabolic Status of Leptin Deficient Mice. The Journal of neuroscience : the official journal of the Society for Neuroscience 33, 840-851, doi:10.1523/JNEUROSCI.3215-12.2013 (2013).

47 Tucker, W. C., Weber, T. \& Chapman, E. R. Reconstitution of Ca2+-regulated membrane fusion by synaptotagmin and SNAREs. Science 304, 435-438 (2004).

48 Weber, T. et al. SNAREpins: minimal machinery for membrane fusion. Cell 92, 759-772 (1998).

49 Zhang, X.-1., Upreti, C. \& Stanton, P. K. G $\beta \gamma$ and the C Terminus of SNAP-25 Are Necessary for Long-Term Depression of Transmitter Release. PLoS ONE 6, e20500.

50 Irwin, S. Comprehensive observational assessment: Ia. A systematic, quantitative procedure for assessing the behavioral and physiologic state of the mouse. Psychopharmacologia 13, 222-257, doi:10.1007/bf00401402 (1968).

51 Ford, C. P. The role of D2-autoreceptors in regulating dopamine neuron activity and transmission. Neuroscience 282, 13-22, doi:https://doi.org/10.1016/j.neuroscience.2014.01.025 (2014).

52 Alford, S., Schwartz, E. \& Prisco, G. V. D. The Pharmacology of Vertebrate Spinal Central Pattern Generators. The Neuroscientist 9, 217-228, doi:10.1177/1073858403009003014 (2003). 
53 Beare, J. E. et al. Gait Analysis in Normal and Spinal Contused Mice Using the TreadScan System. Journal of Neurotrauma 26, 2045-2056, doi:10.1089/neu.2009.0914 (2009).

54 Takao, K. \& Miyakawa, T. Light/dark Transition Test for Mice. Journal of Visualized Experiments : JoVE, 104, doi:10.3791/104 (2006).

55 Yankelevitch-Yahav, R., Franko, M., Huly, A. \& Doron, R. The Forced Swim Test as a Model of Depressive-like Behavior. Journal of Visualized Experiments : JoVE, 52587, doi:10.3791/52587 (2015).

56 Jones, C. K., Peters, S. C. \& Shannon, H. E. Efficacy of Duloxetine, a Potent and Balanced Serotonergic and Noradrenergic Reuptake Inhibitor, in Inflammatory and Acute Pain Models in Rodents. Journal of Pharmacology and Experimental Therapeutics 312, 726-732, doi:10.1124/jpet.104.075960 (2005).

57 Starke, K. Influence of extracellular noradrenaline on the stimulation-evoked secretion of noradrenaline from sympathetic nerves: Evidence for an $\alpha$-receptor-mediated feed-back inhibition of noradrenaline release. Naunyn-Schmiedeberg's Archives of Pharmacology 275, 11-23, doi:10.1007/bf00505064 (1972).

58 Hein, L. Adrenoceptors and signal transduction in neurons. Cell and Tissue Research 326, 541551, doi:10.1007/s00441-006-0285-2 (2006).

59 Altman, J. D. et al. Abnormal Regulation of the Sympathetic Nervous System in $\alpha<\operatorname{sub}>2 \mathrm{~A}<$ /sub $>$-Adrenergic Receptor Knockout Mice. Molecular Pharmacology 56, 154-161, doi:10.1124/mol.56.1.154 (1999).

60 Hein, L., Altman, J. D. \& Kobilka, B. K. Two functionally distinct $\alpha 2$-adrenergic receptors regulate sympathetic neurotransmission. Nature 402, 181, doi:10.1038/46040 (1999).

61 Bouwknecht, J. A., Hijzen, T. H., van der Gugten, J., Maes, R. A. A. \& Olivier, B. Stress-induced hyperthermia in mice: effects of flesinoxan on heart rate and body temperature. European Journal of Pharmacology 400, 59-66, doi:https://doi.org/10.1016/S0014-2999(00)00387-3 (2000).

62 Enero, M. A., Langer, S. Z., Rothlin, R. P. \& Stefano, F. J. E. Role of the $\alpha$-adrenoceptor in regulating noradrenaline overflow by nerve stimulation. British Journal of Pharmacology 44, 672-688 (1972).

63 Egli, R. E. et al. Norepinephrine Modulates Glutamatergic Transmission in the Bed Nucleus of the Stria Terminalis. Neuropsychopharmacology 30, 657-668 (2004).

64 Shields, A. D., Wang, Q. \& Winder, D. G. $\alpha 2$ A-adrenergic receptors heterosynaptically regulate glutamatergic transmission in the bed nucleus of the stria terminalis. Neuroscience 163, 339-351, doi:http://dx.doi.org/10.1016/j.neuroscience.2009.06.022 (2009).

65 Flavin, S. A., Matthews, R. T., Wang, Q., Muly, E. C. \& Winder, D. G. $\alpha 2$ A-Adrenergic Receptors Filter Parabrachial Inputs to the Bed Nucleus of the Stria Terminalis. The Journal of Neuroscience 34, 9319-9331, doi:10.1523/jneurosci.0822-14.2014 (2014).

66 O'Mara, S. The subiculum: what it does, what it might do, and what neuroanatomy has yet to tell us. Journal of Anatomy 207, 271-282, doi:10.1111/j.1469-7580.2005.00446.x (2005).

67 McNamara, R. K. \& Skelton, R. W. Baclofen, a selective GABAB receptor agonist, dosedependently impairs spatial learning in rats. Pharmacology Biochemistry and Behavior 53, 303308, doi:https://doi.org/10.1016/0091-3057(95)02025-X (1996).

68 Morris, R. Developments of a water-maze procedure for studying spatial learning in the rat. Journal of Neuroscience Methods 11, 47-60, doi:https://doi.org/10.1016/0165-0270(84)90007-4 (1984).

69 Takahashi, M., Freed, R., Blackmer, T. \& Alford, S. Calcium influx-independent depression of transmitter release by 5-HT at lamprey spinal cord synapses. J Physiol 532, 323-336 (2001).

70 Gerachshenko, T. et al. Presynaptic G protein-coupled receptors dynamically modify vesicle fusion, synaptic cleft glutamate concentrations and motor behavior. The Journal of neuroscience : the official journal of the Society for Neuroscience 29, 10221-10233, doi:10.1523/JNEUROSCI.1404-09.2009 (2009). 
71 Sorensen, J. B. et al. Differential control of the releasable vesicle pools by SNAP-25 splice variants and SNAP-23. Cell 114, 75-86 (2003).

72 Fang, Q. et al. The role of the C terminus of the SNARE protein SNAP-25 in fusion pore opening and a model for fusion pore mechanics. Proceedings of the National Academy of Sciences 105, 15388-15392, doi:10.1073/pnas.0805377105 (2008).

73 Bao, H. et al. Dynamics and number of trans-SNARE complexes determine nascent fusion pore properties. Nature 554, 260, doi:10.1038/nature25481

https://www.nature.com/articles/nature25481\#supplementary-information (2018).

74 Photowala, H., T. Blackmer, E. Schwartz, H.E. Hamm, and S. Alford. G protein bg-subunits activated by serotonin mediate presynaptic inhibition by regulating vesicle fusion properties. Proc Natl Acad Sci U S A 103, 4281-4286 (2006).

75 Zhao, A. et al. Gao Represses Insulin Secretion by Reducing Vesicular Docking in Pancreatic $\beta$ Cells. Diabetes 59, 2522-2529 (2010).

76 Fang, Q., Zhao, Y., Herbst, A. D., Kim, B. N. \& Lindau, M. Positively Charged Amino Acids at the SNAP-25 C Terminus Determine Fusion Rates, Fusion Pore Properties, and Energetics of Tight SNARE Complex Zippering. The Journal of Neuroscience 35, 3230-3239, doi:10.1523/jneurosci.2905-14.2015 (2015).

77 Schwartz, E. J., Blackmer, T., Gerachshenko, T. \& Alford, S. Presynaptic G-Protein-Coupled Receptors Regulate Synaptic Cleft Glutamate via Transient Vesicle Fusion. The Journal of Neuroscience 27, 5857-5868, doi:10.1523/jneurosci.1160-07.2007 (2007).

78 Gilsbach, R. \& Hein, L. Are the pharmacology and physiology of $\alpha 2$ adrenoceptors determined by $\alpha 2$-heteroreceptors and autoreceptors respectively? British Journal of Pharmacology 165, 90.

79 Gilsbach, R. et al. Genetic Dissection of $\alpha<\mathrm{sub}>2</$ sub $>$-Adrenoceptor Functions in Adrenergic versus Nonadrenergic Cells. Molecular Pharmacology 75, 1160-1170, doi:10.1124/mol.109.054544 (2009).

80 Banihashemi, L. \& Rinaman, L. Noradrenergic Inputs to the Bed Nucleus of the Stria Terminalis and Paraventricular Nucleus of the Hypothalamus Underlie Hypothalamic-Pituitary-Adrenal Axis But Not Hypophagic or Conditioned Avoidance Responses to Systemic Yohimbine. The Journal of Neuroscience 26, 11442 (2006).

81 Freeman, Z. T. et al. Neurocognitive dysfunction and pharmacological intervention using guanfacine in a rhesus macaque model of self-injurious behavior. Translational Psychiatry 5, e567, doi:10.1038/tp.2015.61 (2015).

82 Mineur, Y. S. et al. Antidepressant-like effects of guanfacine and sex-specific differences in c-fos immunoreactivity and paired-pulse ratio in male and female mice. Psychopharmacology 232, 3539-3549, doi:10.1007/s00213-015-4001-3 (2015).

83 Mantsch, J. R. et al. Involvement of Noradrenergic Neurotransmission in the Stress- but not Cocaine-Induced Reinstatement of Extinguished Cocaine-Induced Conditioned Place Preference in Mice: Role for $\beta$-2 Adrenergic Receptors. Neuropsychopharmacology 35, 2165-2178, doi:10.1038/npp.2010.86 (2010).

84 Rasmussen, D. D., Alexander, L., Malone, J., Federoff, D. \& Froehlich, J. C. THE $\alpha(2)-$ ADRENERGIC RECEPTOR AGONIST, CLONIDINE, REDUCES ALCOHOL DRINKING IN ALCOHOL-PREFERRING (P) RATS. Alcohol (Fayetteville, N.Y.) 48, 543-549, doi:10.1016/j.alcohol.2014.07.002 (2014).

85 Erb, S. et al. Alpha-2 Adrenergic Receptor Agonists Block Stress-Induced Reinstatement of Cocaine Seeking. Neuropsychopharmacology 23, 138, doi:10.1016/S0893-133X(99)00158-X (2000).

86 Michaeli, A. \& Yaka, R. Dopamine inhibits GABAA currents in ventral tegmental area dopamine neurons via activation of presynaptic G-protein coupled inwardly-rectifying potassium channels. Neuroscience 165, 1159-1169, doi:http://dx.doi.org/10.1016/j.neuroscience.2009.11.045 (2010). 

in rat cerebral cortex. Journal of Neurochemistry 107, 1506-1517, doi:10.1111/j.14714159.2008.05712.x (2008).

88 Johansson, J. U. et al. An Ancient Duplication of Exon 5 in the Snap25 Gene Is Required for Complex Neuronal Development/Function. PLOS Genetics 4, e1000278, doi:10.1371/journal.pgen.1000278 (2008).

89 Jeans, A. F. et al. A dominant mutation in Snap25 causes impaired vesicle trafficking, sensorimotor gating, and ataxia in the blind-drunk mouse. Proceedings of the National Academy of Sciences 104, 2431-2436, doi:10.1073/pnas.0610222104 (2007).

90 Schwartz, E. J., Gerachshenko, T. \& Alford, S. 5-HT prolongs ventral root bursting via presynaptic inhibition of synaptic activity during fictive locomotion in lamprey. $J$ Neurophysiol 93, 980-988 (2005).

91 Chapman, E. R., Desai, R. C., Davis, A. F. \& Tornehl, C. K. Delineation of the Oligomerization, AP-2 Binding, and Synprint Binding Region of the C2B Domain of Synaptotagmin. Journal of Biological Chemistry 273, 32966-32972, doi:10.1074/jbc.273.49.32966 (1998).

92 Chicka, M. C., Hui, E., Liu, H. \& Chapman, E. R. Synaptotagmin arrests the SNARE complex before triggering fast, efficient membrane fusion in response to Ca2+. Nat Struct Mol Biol 15, 827-835, doi:http://www.nature.com/nsmb/journal/v15/n8/suppinfo/nsmb.1463_S1.html (2008).

93 Cong, L. et al. Multiplex Genome Engineering Using CRISPR/Cas Systems. Science 339, 819 (2013).

94 Yim, Y. Y. et al. Quantitative Multiple-Reaction Monitoring Proteomic Analysis of G $\beta$ and G $\gamma$ Subunits in C57B16/J Brain Synaptosomes. Biochemistry 56, 5405-5416, doi:10.1021/acs.biochem.7b00433 (2017).

95 Mazzoni, M. R., Malinski, J. A. \& Hamm, H. E. Structural analysis of rod GTP-binding protein, Gt. limited proteolytic digestion pattern of Gt with four proteases defines monoclonal antibody epitope. J. Biol. Chem. 266, 14072-14081 (1991).

96 Schindelin, J. et al. Fiji: an open-source platform for biological-image analysis. Nat Meth 9, 676682, doi:http://www.nature.com/nmeth/journal/v9/n7/abs/nmeth.2019.html\#supplementaryinformation (2012).

97 Schindelin, J., Rueden, C. T., Hiner, M. C. \& Eliceiri, K. W. The ImageJ ecosystem: An open platform for biomedical image analysis. Molecular Reproduction and Development 82, 518-529, doi:10.1002/mrd.22489 (2015).

98 Byun, N. E. et al. Antipsychotic Drug-Like Effects of the Selective M(4) Muscarinic Acetylcholine Receptor Positive Allosteric Modulator VU0152100. Neuropsychopharmacology 39, 1578-1593, doi:10.1038/npp.2014.2 (2014).

99 Korpi, E. R. et al. Cerebellar granule-cell-specific GABAA receptors attenuate benzodiazepineinduced ataxia: evidence from $\alpha 6$-subunit-deficient mice. European Journal of Neuroscience 11, 233-240, doi:10.1046/j.1460-9568.1999.00421.x (1999).

100 Phillips, G. R. et al. The Presynaptic Particle Web: Ultrastructure, Composition, Dissolution, and Reconstitution. Neuron 32, 63-77, doi:https://doi.org/10.1016/S0896-6273(01)00450-0 (2001).

101 Betke, K. M. et al. Differential Localization of G Protein $\beta \gamma$ Subunits. Biochemistry 53, 23292343, doi:10.1021/bi500091p (2014). 
A
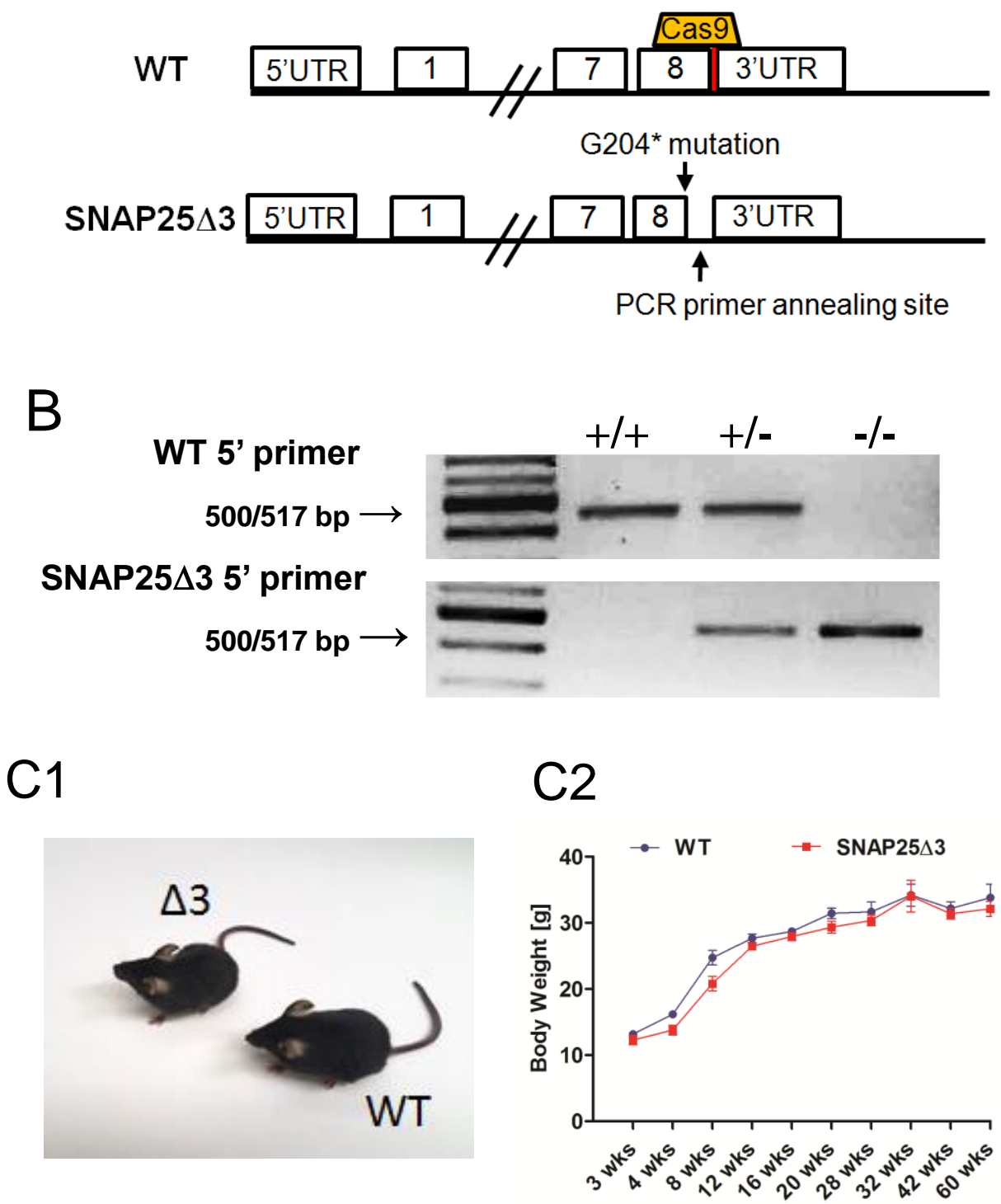

Figure 1. Creation of the SNAP25 $\Delta 3$ mouse via CRISPR-Cas9. 

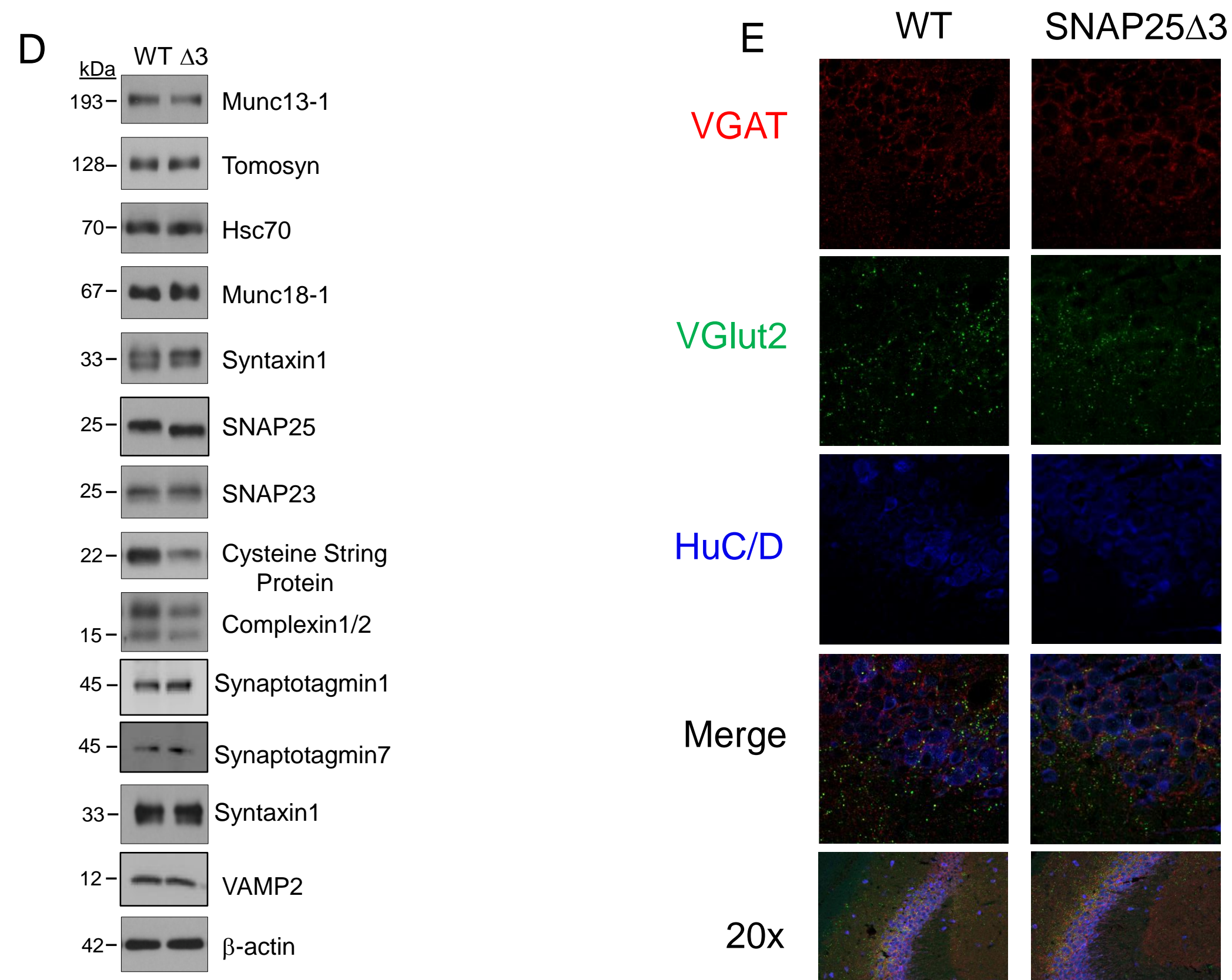

$\mathrm{HuC} / \mathrm{D}$

Merge

Figure 1. Creation of the SNAP25 $\triangle 3$ mouse via CRISPR-Cas9. 
B
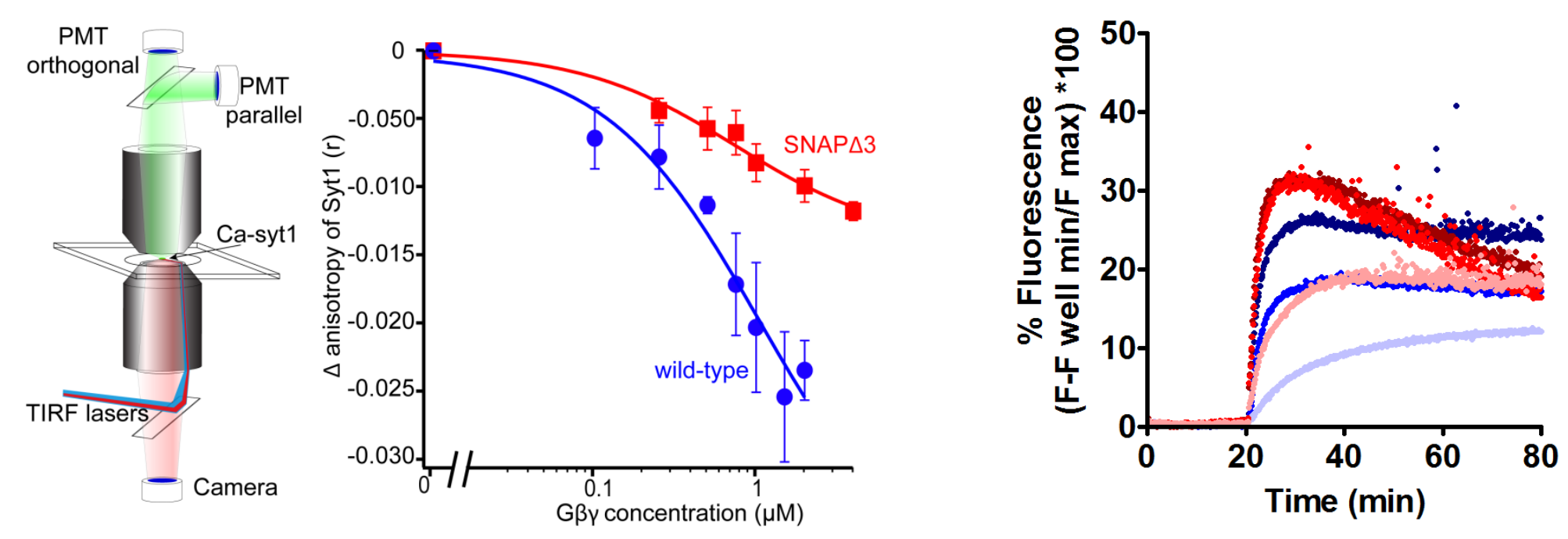

- WT + $0 \mu \mathrm{M} G \beta \gamma$

- WT + $2 \mu \mathrm{M} \mathrm{G} \beta \gamma$

$\mathrm{WT}+6 \mu \mathrm{MG} \beta \gamma$

$\Delta 3+0 \mu M$ G $\beta \gamma$

- $\Delta 3+2 \mu M G \beta \gamma$

$\Delta 3+6 \mu M G \beta \gamma$

C1

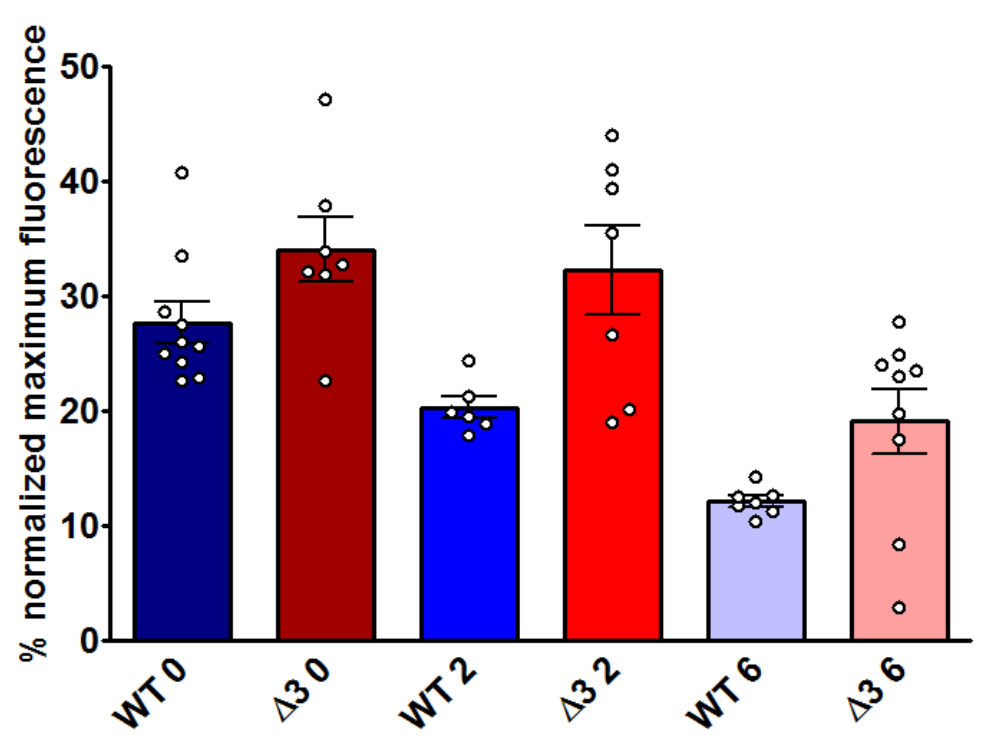

$\mathrm{C} 2$

\begin{tabular}{|ccc|}
\hline Comparison & Significance & p \\
\hline WT $0 \mu \mathrm{M}$ vs. $\Delta 30 \mu \mathrm{M}$ & ns & 0.0604 \\
WT $0 \mu \mathrm{M}$ vs. WT $2 \mu \mathrm{M}$ & $* *$ & 0.0083 \\
$\Delta 30 \mu \mathrm{M}$ vs. $\Delta 32 \mu \mathrm{M}$ & $\mathrm{ns}$ & 0.7102 \\
WT $0 \mu \mathrm{M}$ vs. WT $6 \mu \mathrm{M}$ & $* * *$ & $<0.001$ \\
$\Delta 30 \mu \mathrm{M}$ vs. $\Delta 36 \mu \mathrm{M}$ & $* *$ & 0.0021 \\
WT $2 \mu \mathrm{M}$ vs. $\Delta 32 \mu \mathrm{M}$ & $*$ & 0.0175 \\
WT $6 \mu \mathrm{M}$ vs. $\Delta 36 \mu \mathrm{M}$ & $*$ & 0.0461 \\
\hline
\end{tabular}

Figure 2. SNAP $25 \Delta 3$ impairs G $\beta \gamma$ competition with synaptotagmin I and inhibition of calcium-synaptotagmin I-mediated liposome fusion. 
A1

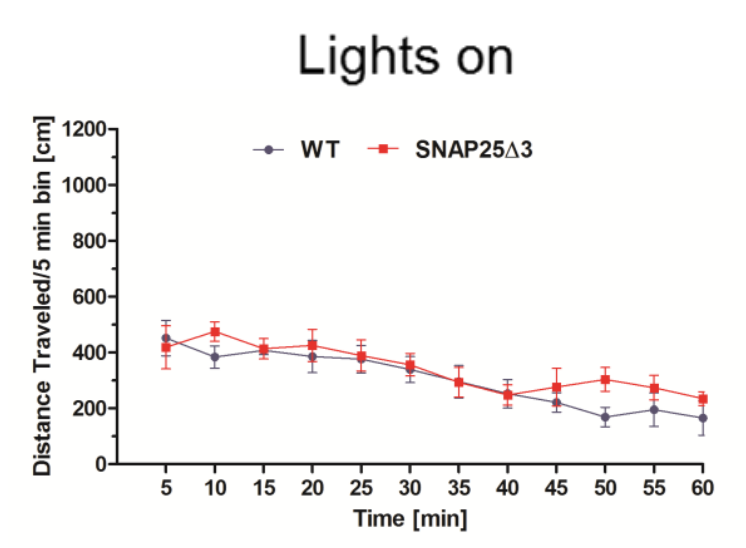

C

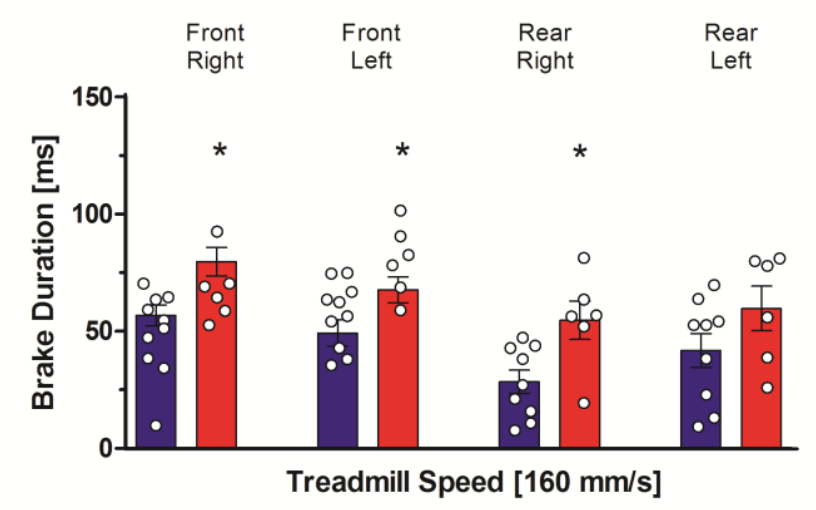

B
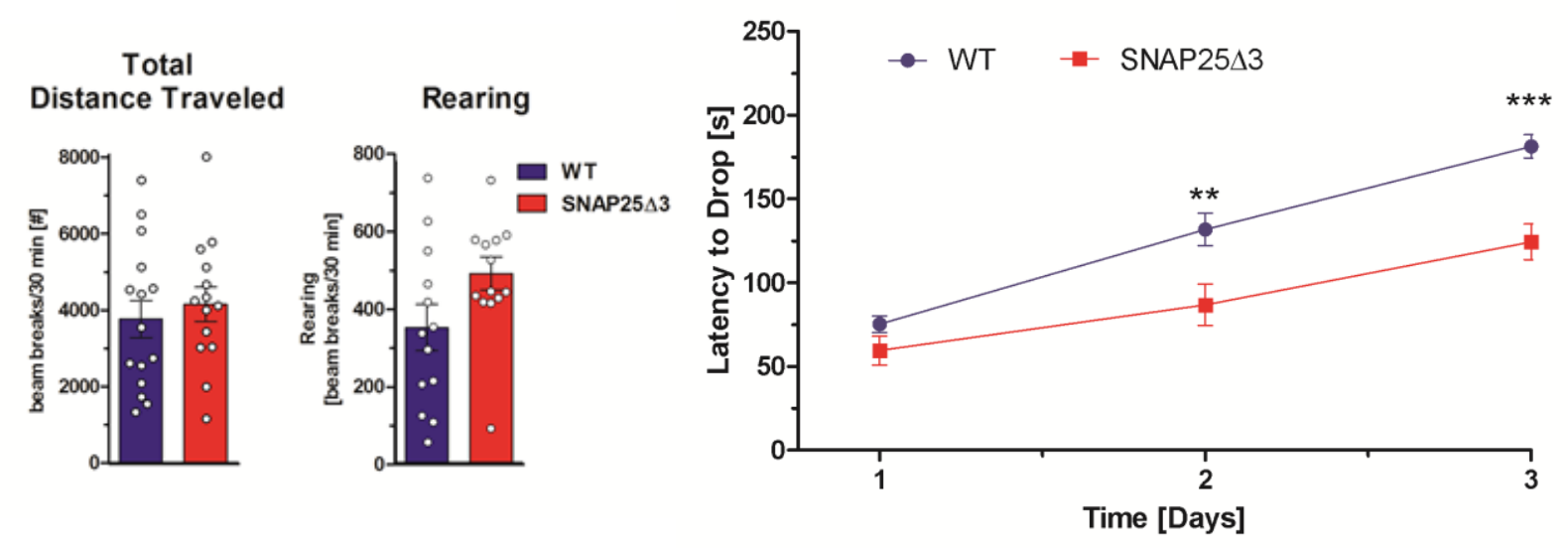

D

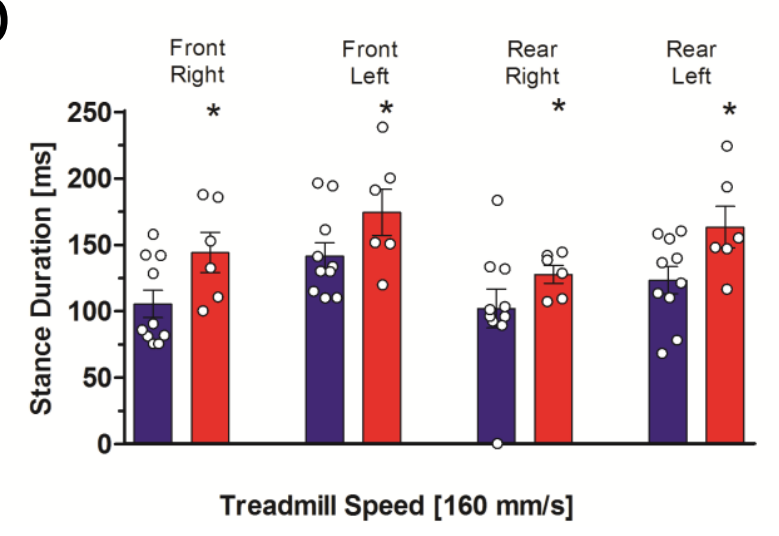

Figure 3. SNAP25 $\triangle 3$ mutant mice have impaired motor coordination and altered gait. 

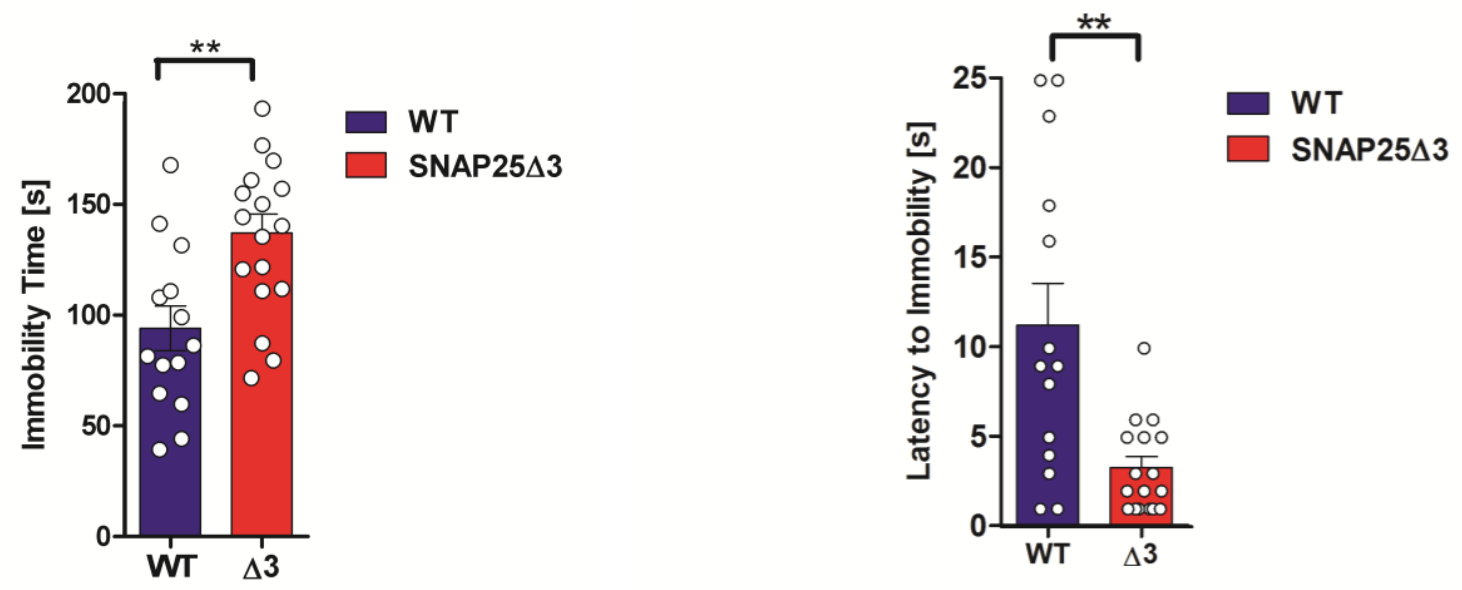

\section{B1}

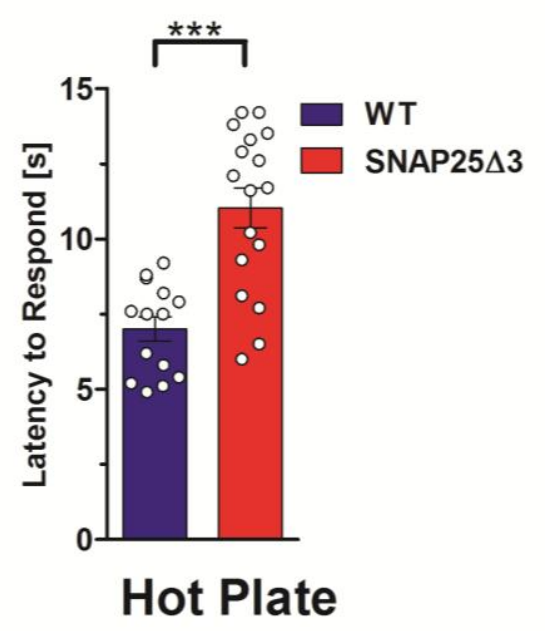

B2

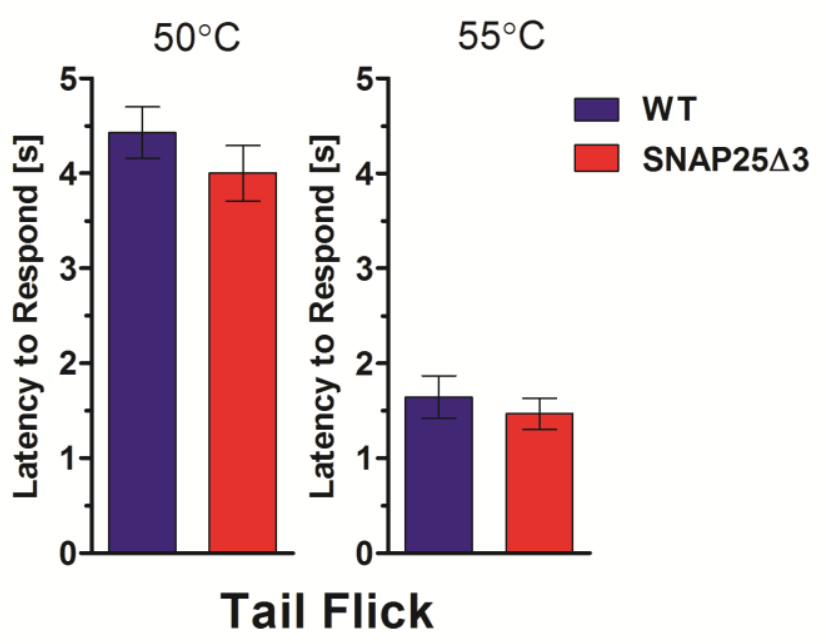

Figure 4. SNAP25 $\triangle 3$ mutant mice showed altered affect and supraspinal nociception. 
A

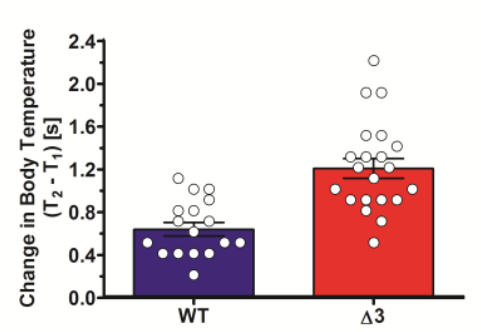

B

BNST

neuron
C

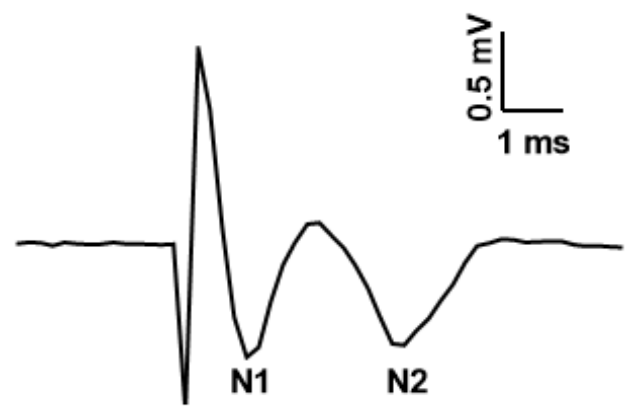

D

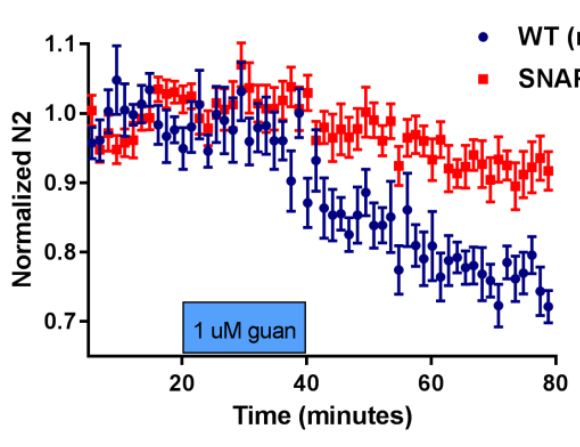

F

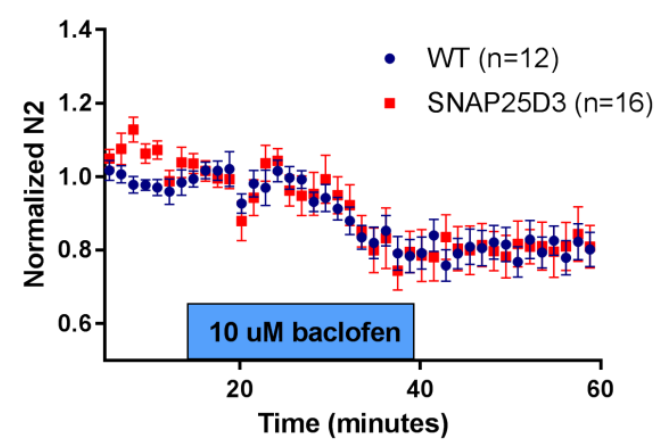

E

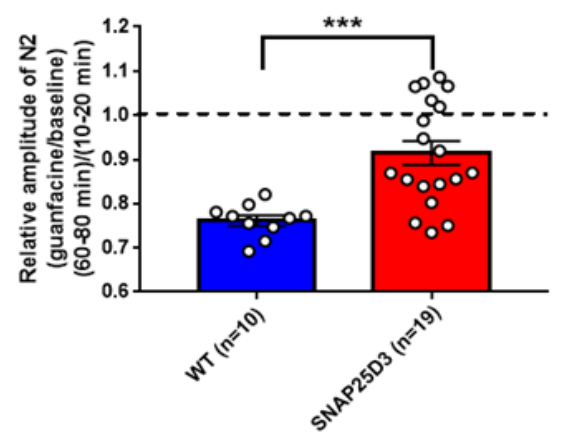

G

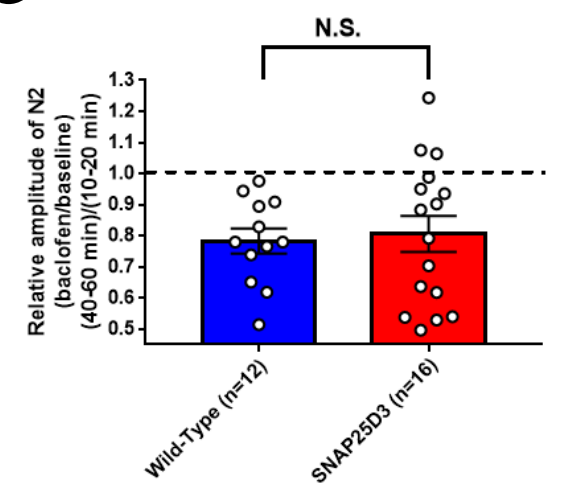

Figure 5: SNAP25 $\Delta 3$ mice have altered stress responses and impaired $\alpha 2 a$ heteroreceptor signaling in the BNST. 


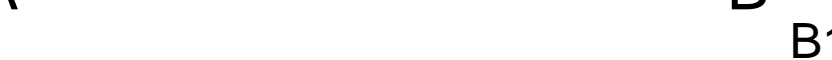

B1

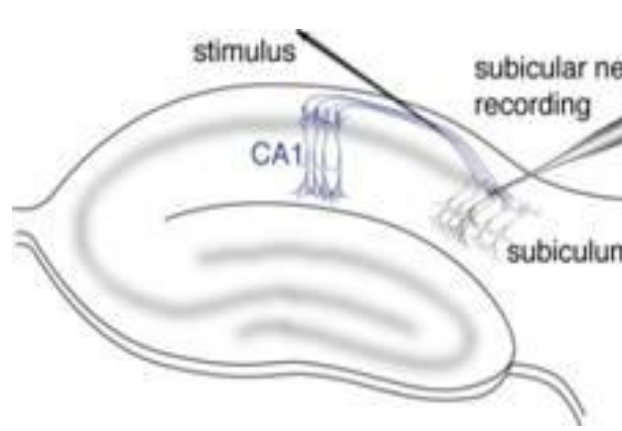

B2

Wild-type

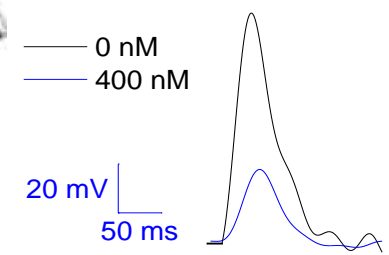

B3

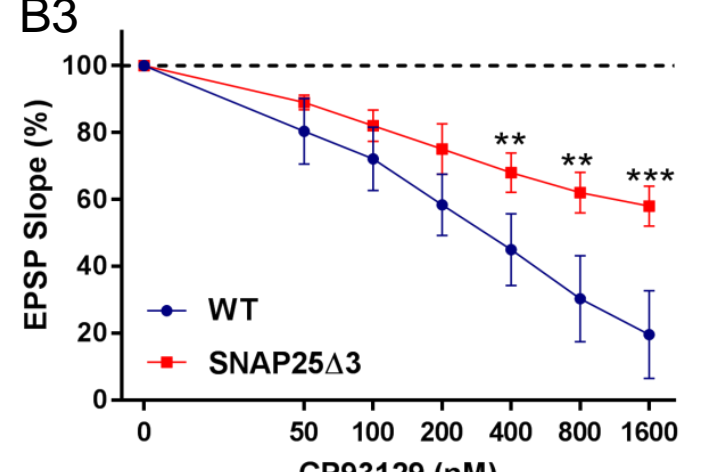

C3

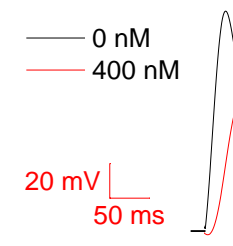

SNAP25 23

C1

C2

Wild-type

SNAP25 $\triangle 3$
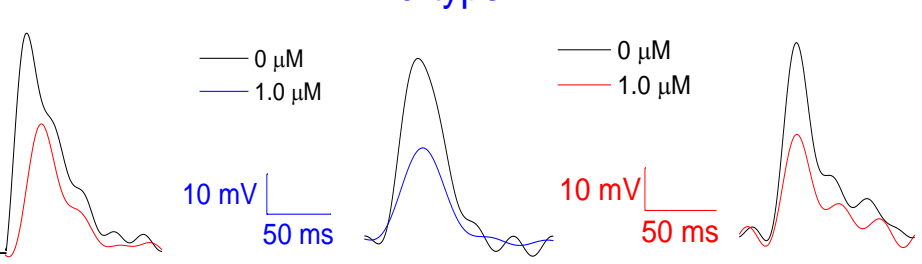

D

CP93129 (nM)
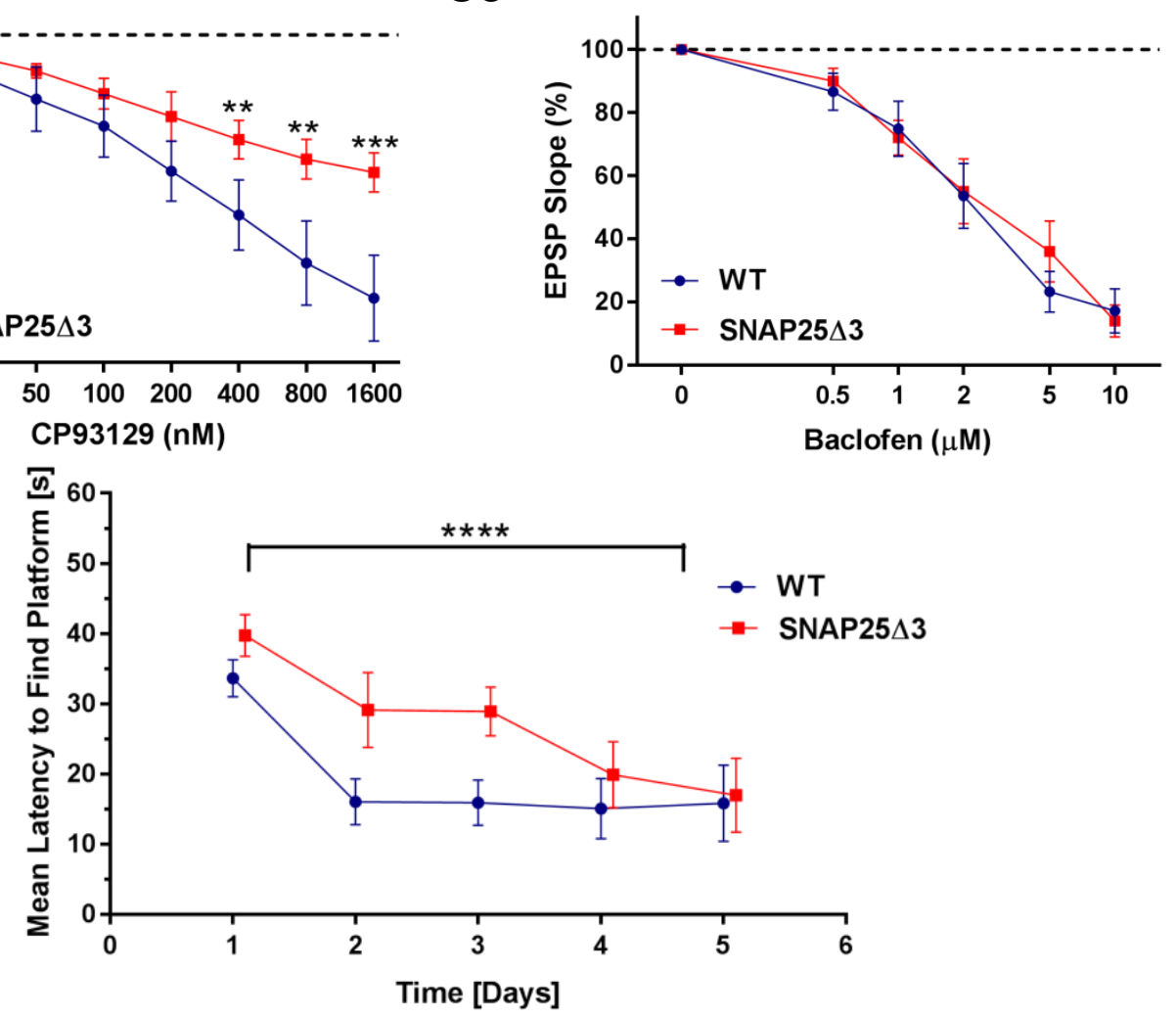

Figure 6. SNAP $25 \triangle 3$ homozygotes have impaired $\mathrm{G}_{\mathrm{i} / \mathrm{o}^{-}}$-coupled GPCR signaling in CA1/subiculuar hippocampal neurons and show impaired hippocampal spatial learning. 
A
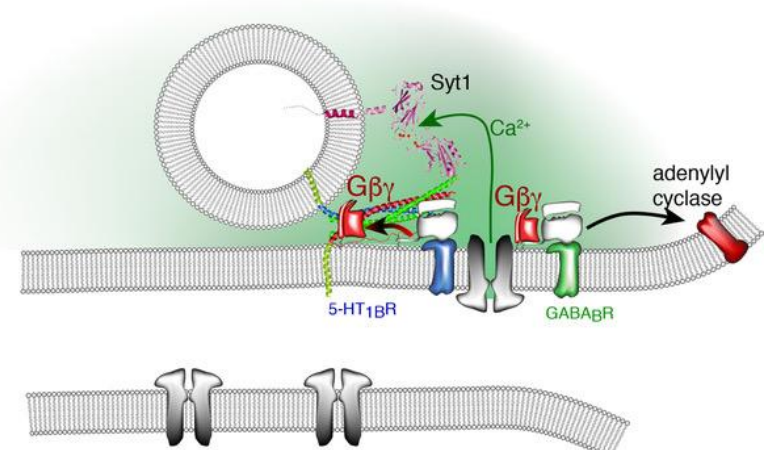

B
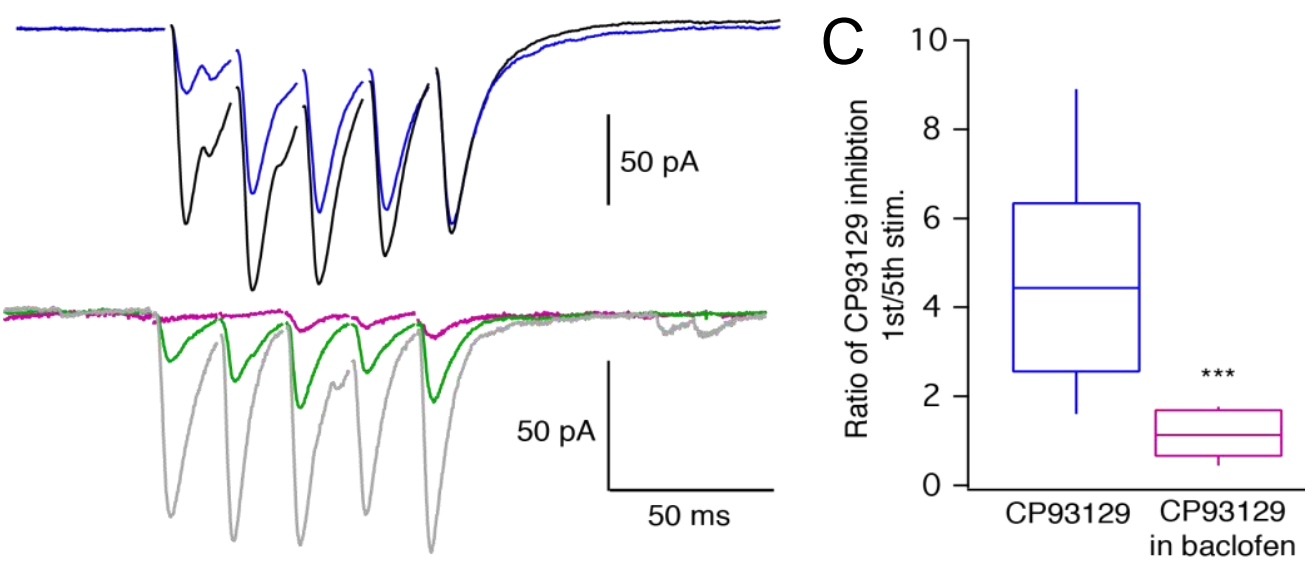

Figure 7. Synergy between $5-\mathrm{HT}_{1 \mathrm{~B}}$ and $\mathrm{GABA}_{\mathrm{B}}$ at the $\mathrm{CA} 1$ /subicular synapse. 